4 norden 



\section{Mobility Management in the Nordic Countries}

Ann-Sofie Atterbrand, Brita Jorde, Olav Kasin, Thomas Krag, Björn Silfverberg, Johanna Skur, Maija Stenvall

TemaNord 2005:539 
Mobility Management in the Nordic Countries

TemaNord 2005:539

(C) Nordic Council of Ministers, Copenhagen 2005

ISBN 92-893-1167-3

This publication can be ordered on www.norden.org/order. Other Nordic publications are available at www.norden.org/publications

Printed in Denmark

Nordic Council of Ministers

Store Strandstræde 18

DK-1255 Copenhagen K

Phone (+45) 33960200

Fax $(+45) 33960202$

www.norden.org

\author{
Nordic Council \\ Store Strandstræde 18 \\ DK-1255 Copenhagen $\mathrm{K}$ \\ Phone (+45) 33960400 \\ Fax $(+45) 33111870$
}

\section{Nordic co-operation in the transport sector}

The overall, general objective of co-operation is to foster a Nordic transport sector characterised by efficiency, competitiveness, safety, sustainability, and equality. In order to attain these objectives with the resources available, co-operation will be focussed on four areas:

Sustainable Mobility, The Baltic Sea, Intelligent Transport Systems and Transport Safety.

\section{Nordic co-operation}

Nordic co-operation, one of the oldest and most wide-ranging regional partnerships in the world, involves Denmark, Finland, Iceland, Norway, Sweden, the Faroe Islands, Greenland and Åland. Cooperation reinforces the sense of Nordic community while respecting national differences and similarities, makes it possible to uphold Nordic interests in the world at large and promotes positive relations between neighbouring peoples.

Co-operation was formalised in 1952 when the Nordic Council was set up as a forum for parliamentarians and governments. The Helsinki Treaty of 1962 has formed the framework for Nordic partnership ever since. The Nordic Council of Ministers was set up in 1971 as the formal forum for co-operation between the governments of the Nordic countries and the political leadership of the autonomous areas, i.e. the Faroe Islands, Greenland and Åland. 


\section{Content}

Abbreviations and terminology ....................................................... 7

Foreword ........................................................................................... 9

Summary ….............................................................................. 11

1. Introduction ..................................................................................... 13

1.1 The Background and Aim of the Study .................................... 13

1.2 Survey Methods and Study Structure ............................................. 14

1.3 Subscribers and Consultants ............................................................. 14

2. The Concept of Mobility Management ................................. 17

2.1 Main Aims of Mobility Management ........................................... 17

2.2 Terminology in The Nordic Countries .......................................... 17

2.3 Mobility Management in European Union

Transport Policy ................................................................................ 19

3. The Role of Mobility Management in Nordic

Transport Policy ................................................................................ 21

3.1 Active Partners and Their Reason to Act ................................. 21

3.2 Main Political Arguments ................................................................. 23

3.3 Role of Companies and Labour Organisations .......................... 24

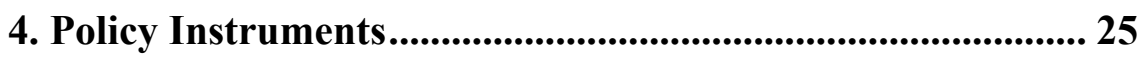

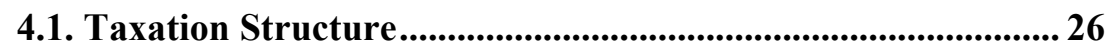

4.2 National and Local Planning and Building Regulations ......... 33

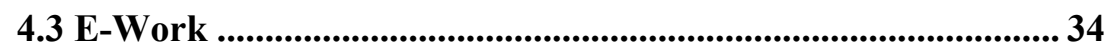

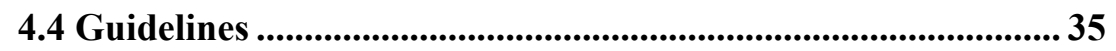

5. Mobility Management Actions Related to Commuting ....... 37

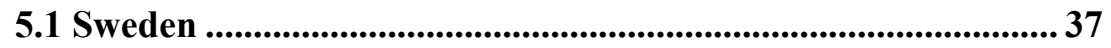

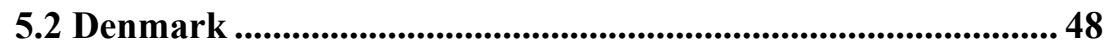

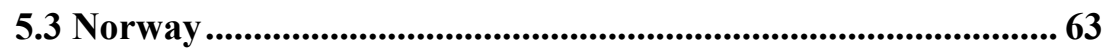

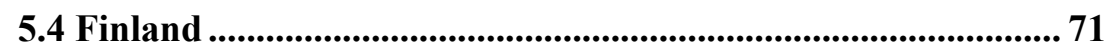


6. Future Promotion of Mobility Management in the Nordic Countries ........................................................................... 75

6.1 Developing Policy Instruments ................................................... 76

6.2 Cooperation actions ..................................................................... 78

6.3 Developing evaluation methods .................................................... 80

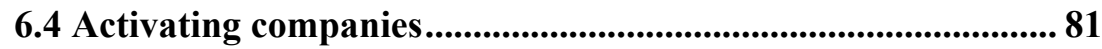

7. Appendices ........................................................................................ 85

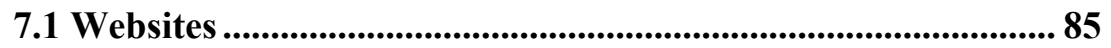

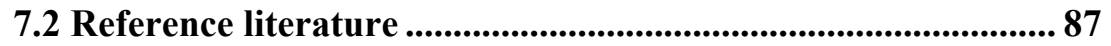

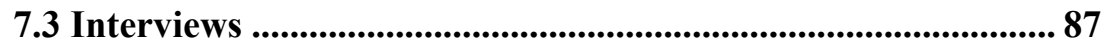




\title{
Abbreviations and terminology
}

\author{
Abbreviations \\ EA European co-operation for Accreditation. \\ ECMT European Conference of Ministers of Transport \\ ECOMM European Conference on Mobility Management. \\ EFQM The primary source for organisations throughout Europe \\ which are looking for more than quality, but are also \\ striving to excel in their market and in their business. \\ EFQM is the creator of the prestigious European Quality \\ Award. \\ EMAS The Eco-Management and Audit Scheme. \\ EPOMM European Platform on Mobility Management \\ Iqnet The International Certification Network. \\ ISO International Organisation for Standardisation. \\ OECD Organisation for Economic Co-operation and \\ Development \\ UNECE Economic Commission for Europe of the United Nations \\ WHO World Health Organisation \\ Terminology \\ Car sharing:
}

A car sharing company owns cars and provides car use services. Persons and companies can be paid members in such company giving possibility to use car for mainly sporadic use.

Car pooling:

Several passengers in somebody's privately owned car.

Company Mobility Management:

The expression used for Mobility Management activities implemented in companies and workplaces.

Mobility Management:

A new concept to promote sustainable transport. The core of Mobility Management are "soft" measures (e.g. information or coordination of existing user services), which enhance the effectiveness of "hard" measures of traffic planning (e.g. new roads). The objective of Mobility Management is to reduce single car use.

Mobility Office:

A service point for environmentally sustainable transport. Office can gather and spread information, launch projects and activate various counterparts to Mobility Management actions. 



\section{Foreword}

Mobility Management aims to promote sustainable modes of transport and to reduce demand of motorised transport by cooperation between various actors. In this respect it also provides an efficient tool for promoting physical health and reducing negative environmental impacts caused by transport.

The Nordic Council of Ministers financed the project "Mobility Management in Nordic countries" and the Council's thematic group "Hållbar Mobilitet" supervised it. The aim of the project was to collect, analyse and distribute information on Mobility Management activities and policy instruments related to commuting in Sweden, Denmark, Norway and Finland. The recommendations for future promotion are formulated by the authors and do not represent the official opinion of the Nordic Council of Ministers.

All Nordic countries have introduced activities in view of promoting Mobility Management. The report shows that the Nordic countries may learn from each other when aiming at promoting Mobility Management. Most of these measures should be taken at the local and company level, but there is also a role for international community and national authorities to play in order to create a more favourable environment for Mobility Management. 



\section{Summary}

Mobility Management is a broad concept, the objective of which is to reduce dependence on the private car for personal transport. The basic means of achieving this are offering better information about alternative transport modes and more attractive services. The central aim is to encourage actors that generate traffic to develop various ways to promote public transport, cycling, walking, car pooling, car sharing, E-work etc. There is a wide range of measures available to select from: public transport information, employer paid public transport, car parking regulation, company bicycles etc.

The most active counterparts, promoting Mobility Management in The Nordic Countries, have been the ministries of transport and environment. The National Road Administration has played a key role especially in Sweden. The European Union has also acknowledged Mobility Management as an approach that is in line with an overall demand-oriented strategy to tackle traffic problems in a sustainable way. Many national and local regulations and guidelines affect commuter transport and especially the choice of transport mode. Income tax, the key policy instrument at the national level, falls within this context. At the local level, instruments mainly relate to physical preconditions with parking supply being accentuated. Car parking at work places is considered as a taxable fringe benefit in Sweden within certain limits.. Company cars, operating within an environmental frame, are favoured in Swedish taxation.

In Sweden Mobility Management services are often provided by a local traffic office (Trafikkontor). Solutions developed for Gothenburg and Lund are presented in this report. One of the largest Danish Mobility Management related projects, "The Bike Busters Århus", was introduced as early as 1995. The commuter oriented "Pendlerkontor" in Copenhagen was established in 2002 in order to provide transport planning services to companies and public organisations. The SMART project in Norway activated several companies to carry out Mobility Management schemes in the Oslo area. In Finland a variety of local projects has been carried out and the interest in Mobility Management is growing rapidly. 
When launching a Mobility Management project it is important to show direct financial benefits for the companies involved. They commonly derive from savings related to car parking and improved health of employees. Personal health is usually the main motivating factor for employees. Clear support from management is vital to ensure continuity of the work. The national authorities can support companies by developing the policy instruments, financing practical pilot projects and disseminating information on best practices. The Nordic Countries share a range of common features that motivate future co-operation in the field of Mobility Management, leading along the path towards sustainable transport. 


\section{Introduction}

\subsection{The Background and Aim of the Study}

When striving to reduce private car dependence many different and optional ways of travelling are needed. The Mobility Management concept points out that the private sector (employers, organizers of special events etc.) could and should carry its responsibility for offering a wide variety of travel modes: favouring those that have the least harmful impacts on the environment and that possibly have positive effects on public health. Reducing private car dependence is not the sole responsibility of public administrations.

A problem in setting up a Mobility Management programme has been that the different tools for planning and implementation do not clearly fit into any traditional organisational segment. Also, the direct benefits of Mobility Management initiatives are quite difficult to demonstrate and calculate. That is probably the reason why employers usually do not offer any other transport services than normal car parking or company cars. As these tools are supported and justified by building regulations and tax codes, they are normal and accepted. Many other tools have not been used because there has not been sufficient demand for them.

Mobility Management is of growing interest in Scandinavia. Sweden especially has been very active in launching practical projects, the results of which have been quite promising. The Swedish National Road Administration, in fact, also initiated this project. With other The Nordic Countries also carrying out several surveys and pilot projects, the theme has a strong potential to develop further. The Nordic Countries could well utilise the experiences gained from each other because of common societal features, city structure, company culture and natural conditions.

The aim of the project was to:

A. Collect, analyze and inform on Nordic Mobility Management activities related to commuter traffic.

B. Provide an overview of and make recommendations on policy instruments related to Mobility Management in The Nordic Countries.

C. Evaluate the impacts of Mobility Management actions and identify the most effective ones.

D. Strengthen national as well as Nordic cooperation in Mobility Management. 
The main focus of this work is on commuter traffic. This topic has been widely studied but still needs much more development. This specific area of Mobility Management could be a forerunner when widening the implementation of Mobility Management to encompass e.g. leisure time travel.

\subsection{Survey Methods and Study Structure}

The project was carried out in two phases. In the $1^{\text {st }}$ phase Mobility Management and related policy instruments were reviewed on a national basis. This included the preparation of case studies that formed the central task in the $2^{\text {nd }}$ phase. Interviews supplemented literature reviews in phase 2 .

In this report, chapter 2 provides an overview of the Mobility Management concept and its interpretation. Chapter 3 analyses the role of Mobility Management in Nordic and EU transport policy. The policy instruments affecting commuter transport and especially modal split are introduced in chapter 4. Examples of Mobility Management projects and actions are described in chapter 5. Finally, chapter 6 gives recommendations for future promotion of Mobility Management in The Nordic Countries.

\subsection{Subscribers and Consultants}

The Nordic Council of Ministers financed the project and the Council's thematic group "Hållbar Mobilitet" supervised it. Group members were:

Sweden: Stefan Andersson (chairman)

Denmark: Lars Olsen Hasselager, Peder Mandrup Knudsen

Norway: Ole Hagen, Trond Kråkenes

Finland: Risto Saari, Leena Silfverberg

Iceland: Johan Gudmundsson

Nordic Council of Ministers: Helena Wallin 
The main contractor was WSP LT-Consultants Ltd (Finland) and it was assisted by country subcontractors (Sweden, Denmark, and Norway):

Finland: Maija Stenvall (Project Manager), Björn Silfverberg/ WSP LT-Consultants Ltd.

Sweden: Phase 1. Ann-Sofie Atterbrand (neé Nilsson), Phase 2. Johanna Skur / WSP Sweden

Denmark: Thomas Krag/ Thomas Krag Mobility Advice

Norway: Phase 1. Olav Kasin/ Syklistenes Landsforening. Phase 2. Brita Jorde/ NatUrban

The lay-out of the report is made by Natalia Martamo and language checking by Peet Ranniste at WSP LT-Consultants. 



\section{The Concept of Mobility Management}

\subsection{Main Aims of Mobility Management}

The central idea of Mobility Management is to develop a package of voluntary actions to reduce the dependency on the private car and to encourage the use of other transport modes. The term Mobility Management can be seen as a set of "soft measures" aiming at promoting sustainable and healthy travel. Infrastructure investments and construction are not normally included in the Mobility Management concept. Minor investments in cycling facilities or information systems, however, can be part of a larger concept. In this study the main prerequisites for Mobility Management were set as follows:

- It should consist of several actions and services as an alternative to single private car use (cycling, public transport, car pooling and sharing, E-work etc)

- Actors should be those who generate traffic (workplaces, mass-events, schools, shopping malls etc.)

- Actions are voluntary to end-users

In addition to the measures falling under the categories above, there is a range of "supporting measures" that are the responsibility of the public administration (requirement in building permits, principles of taxation benefits etc.). These policy instruments define the general boundary conditions that Mobility Management actions and different actors can take.

\subsection{Terminology in The Nordic Countries}

The international English term "Mobility Management" although used quite often in The Nordic Countries, has a different interpretation, scope and focus in each country. Each has its own translation of the concept.

The concepts of "car-sharing" and "carpooling" relate closely to commuting issues. Car-sharing means a system where a private or public company owns the cars and the users buy the right to use them. The users normally pay the running costs of a single trip according to kilometres travelled or time spent. Carpooling comes into play if a person gives a lift to another person in his/her own car. Carpooling is normally organised by 
the persons themselves without any mediators. Carpooling services, however, can be provided via Internet or a company's intranet.

Sweden

Mobility Management is becoming more and more known as a planning tool in Sweden and the concept incorporates many initiatives. In Swedish, the terms "hållbart resande" (sustainable travel) and "miljöanpassade transporter" (environmentally friendly transport) are well known and often referred to within the Mobility Management community.

\section{Denmark}

In Denmark the terms "transportplaner", "transportplaner for virksomheder" and "pendlerplaner" are the most frequently used. Experts so far exclusively use the term "Mobility Management" and the Danish translations "mobilitetsstyring", mobilitetsledelse and trafikledelse. The whole idea of Mobility Management is considered to be abstract by non-experts, and there is a strong tendency to talk about specific issues such as public transport, park \& ride and cycling rather than about the concept as such. Many activities that could be regarded as Mobility Management are thus marketed in other ways, one example being the Danish bicycle to work campaign (Vi cykler til arbejde).

\section{Norway}

The term Mobility Management is not applied very actively in "official" transport policy in Norway, as a way of reducing private car use and promoting public transport, cycling, walking and car-sharing. The term, however, is still used in relation to some pilot projects in 5-6 cities (e.g. Oslo, Stavanger and Kristiansand). The approach is not generally recognised and thus not integrated into the transport planning context. A more common, but not that broadly developed concept as Mobility Management, is "green transport plan", "environmentally friendly transport" or "person and company directed efforts".

\section{Finland}

In Finland Voluntary based actions are highlighted instead of mobility "management". The English term is still used quite often, especially among researchers and those having international connections. Also the term "green commuter plan" has been used but its linkage to solely environmental matters has proven to be problematic. Thus other terms are nowadays favoured, most often "liikkumisen ohjaus". 
More important than a clear and absolute definition of Mobility Management, however, is that all actions should decrease the act of driving alone. Evaluating the effects is critical and the most important indicator is the change in modal split.

\subsection{Mobility Management in European Union Transport Policy}

The European Union has acknowledged the importance of Mobility Management. The importance of a demand oriented strategy (such as Mobility Management) is understood to be an approach of equal importance to other transport tools for tackling traffic problems. As a sign of its advocacy on this matter, in 2001 the European Parliament established a mobility centre within parliament itself.

The White Paper on Common Transport Policy (2001) mentions the need to "make the alternatives to the car more attractive in terms of both infrastructure (metro lines, trams, cycle racks, priority lanes of public transport) and service (quality of service, information give to users)".

The Commission has financed and supported many research and development projects in programmes such as SAVE (17 projects on Mobility Management during 1996-2001), LIFE (including "In town without my car" initiative and European Mobility Week), INTERREG (OPTIMUM 1-2 and TARGET dealing with spatial planning and travel awareness respectively). The $4^{\text {th }}$ Framework programme included the MOMENTUM and MOSAIC projects. The STIR programme is examining new urban transport modalities. Mobility Management is also part of the "Sustainable Surface Transport" theme of the European Commission's $6^{\text {th }}$ Framework Programme (2002-2006).

Good networking actions dealing with Mobility Management are e.g. ACCESS (Euro cities for a New Mobility Culture) and EPOMM (European Platform on Mobility Management).

The European Commission has identified (in "EU-Wide Review of Transport Charges and Taxes (National) in Commuter and Business Travel") that the fiscal barriers to successful development of Mobility Management in Europe are particularly linked to both personal income and company taxation codes. Company taxation includes e.g. company cars, taxation of public transport fares, and free car parking facilities. In terms of income taxation, a financial benefit to people living further away from their job is one example.

The UNECE and WHO Pan-European Programme on Transport, Environment and Health (the PEP) also emphasises the need to prepare national and local plans for promoting public transport, cycling and walking in order to reduce the negative impacts of transportation and to promote physical health. The PEP programme aims at enhancing exchange of 
information on good practises on sustainable and healthy travel policies by creating a Clearing House for this purpose. As Mobility Management provides a tool for national and local authorities to promote sustainable mobility and health, any information on good practises in this area should be provided also for the use of the PEP Clearing House.

The European Conference of Ministers of Transport (ECMT) published in 2002 a report "Implementing Sustainable Urban Travel Policies". Within it, ECMT emphasised the need for flexible and integrated policy packages of which all levels of Government and other partners have important roles in the planning and implementation of. The national government should seek partnerships with different stakeholders in the transport system, including businesses, employers, residential and commercial land developers and associations. Moreover, effective communication and exchange of information is needed in winning support for demand management policies.

From The Nordic Countries the National Road Administration of Sweden is a member of EPOMM (European Platform on Mobility Management) and Sweden has been a partner in several EU projects. Göteborg (Vision Lundby case) has been a partner in three EU projects: CIVITAS (Lundby Mobility Centre), TELLUS (freight transport), and TARGET (travel awareness, especially cycling in Lundby). The City of Lund (LundaMAT's case) has been a partner in the MOST project (mobility centre and evaluation process). A EU-supported (TARGET programme) Mobility Management project is currently ongoing in Odense, Denmark. The project is focusing on influencing travel habits of the employees at Odense University Hospital. Other The Nordic Countries have not been involved in EU projects in the field of Mobility Management. 


\section{The Role of Mobility Management in Nordic Transport Policy}

\subsection{Active Partners and Their Reason to Act}

\section{Sweden}

The Swedish National Road Administration (SNRA) has been assigned the sector responsibility for road transport and thereby is accountable for all development within this sector. A number of County Councils, as well as several municipalities, have Mobility Management projects in progress. Since the municipalities are legally responsible for urban development and environmental matters, they are dealing with Mobility Management issues. According to www.mobilitymanagement.se there are 16 municipalities that have implemented Mobility Management actions. Mobility centres (Trafikkontor) have been set up in 7 municipalities.

The Mobility Management efforts are undertaken due to a number of reasons. Environmental concerns are the strongest ones and are based on 15 quality objectives for sustainability of the environment in the long term. Other reasons are road safety, economics and health.

\section{Denmark}

The Danish Environmental Protection Agency (Miljøstyrelsen), under the Ministry of Environment, has co-funded some Mobility Management related projects along with the National Association of Municipalities. The Ministry of Transport has also dealt with the item to some extent. A former action plan to reduce $\mathrm{CO}_{2}$ emissions in the transport sector included the development and implementation of a transport plan for public institutions and companies among its measures. Since 2002, however, there is no specific $\mathrm{CO}_{2}$ reduction strategy for the Danish transport sector.

Several municipalities have initiated projects. A mobility office was in place in Hillerød until 2001. In Odense, a Centre for Mobility and Environment was set up, which has now developed into the consultancy Cogita. More than 100 municipalities support a central database "Pendlernet" for ride-sharing.

The Greater Copenhagen Authority (HUR - Hovedstadens Udviklingsråd) set up its HUR Pendlerkontor (GCA Commuter Office) in 2002. 
The office has a staff equivalent to 3-4 full-time persons and is by far the most ambitious project of its kind in Denmark.

Environmentally oriented enthusiasts, among them "Green Guides" (employed under a programme of the former Danish government), have also taken initiatives to develop transport plans locally.

\section{Norway}

Norwegian NGO's play an important role in developing Mobility Management projects in Norway. The Norwegian Bicycle Federation, the Norwegian Automobile Federation, a public transport company in Oslo and a private car-sharing organisation are working together on a pilot project (SMART) in a suburb of Oslo. The Ministry of Environment and the National Road Authority provide contribute by financing developing tools and methods as well as supporting local pilot projects.

Some local authorities are important counterparts, as they support pilot projects. The Institute for Transport Economics has carried out some research on Mobility Management.

\section{Finland}

The most active counterparts are the Ministry of Transport and Communications, the Ministry of Environment, and Helsinki Metropolitan Area Council's Transport Department. Also the Finnish Road Administration has financed projects related to Mobility Management. All projects can be categorised as being research projects. Basic data about travel behaviour in companies as well as information from European examples has been collected. A few years ago a brochure on walking and cycling to work at the national and local level was produced by the Ministry of Transport and Communications. The brochure was distributed to the biggest employers.

The City of Tampere has financed one research project on the topic and also the City of Helsinki has co-financed some Mobility Management research projects together with the relevant ministries. A Finnish car share company, City Car Club, operates in the Helsinki area and has now begun to expand to other The Nordic Countries as well.

The importance of Mobility Management has been highlighted in many sector policy programs in the Ministry of Transport and Communications. Examples in addition to the general statement that "companies should be activated to Mobility Management actions" are the National Bicycle Policy Programme, National Strategy on Public Transport, and different strategic programmes that focus on transport and its environmental impacts, especially $\mathrm{CO}_{2}$ emissions.

The Finnish National Commission on Sustainable Development has identified the Mobility Management theme in its action plan for 2004. 
The Commission acts as a forum where different stakeholders (ministries, associations, etc) present their ideas, goals and programmes and engage in a broad debate about sustainability. Also a EU funded training programme for local energy agencies and actors in transport and sustainable energy actions is in the planning phase. This will be a three-year project where local energy offices could improve the knowledge on sustainable transport information services for companies.

The following table 1 summarizes the activeness of different counterparts on Mobility Management issues. The role may be higher for some counterparts if also various single measures to promote different transport modes are assessed. This table indicates only actions that have been launched under the term Mobility Management.

Table 1. Different counterparts in Mobility Management in The Nordic Countries.

\begin{tabular}{|l|r|r|r|r|}
\hline Partner & Sweden & Denmark & Norway & Finland \\
\hline Ministry of Transport & $x x$ & $x x$ & & $x x$ \\
\hline Ministry of Environment & & $x x$ & & $x x$ \\
\hline Road Administration & $x x$ & $x x$ & $x x$ & $x$ \\
\hline Association of Municipalities & $x$ & $x x$ & $x$ & \\
\hline Regional administrations & & $x$ & & $x$ \\
\hline Municipalities & $x x$ & $x$ & $x$ & \\
\hline Non-Governmental Organizations & & & $x$ & \\
\hline
\end{tabular}

xx substantial role (compared to other parties in same country)

$x$ minor role

empty, has not been active.

\subsection{Main Political Arguments}

The ministries have acted mainly on the $\mathrm{CO}_{2}$ issue. At the municipal and regional level green arguments, first and foremost reduction of $\mathrm{CO}_{2}$, have had importance. Road traffic congestion, however, has become a more important argument. Severe congestion problems can be relieved by a small change in traffic volumes and big infrastructure investments thus can be saved by a behavioural change among the transport users.

For the businesses, lack of parking spaces and practical transport problems for the employees serve as the main arguments for action. Interest is, in particular, big in connection with business relocation decisions. Only a few businesses have used green arguments. Health, on the other hand, often plays a role for engagement in cycling activities.

Enthusiastic individuals are usually driven by arguments of sustainability. When it comes to cycle promotion at businesses, enthusiasm in cycling and the wish to create a good spirit among the colleagues are 
important driving forces for the actors. Health issues have become an important argument in marketing the Mobility Management approach.

\subsection{Role of Companies and Labour Organisations}

The Ministry of Labour and the employer and employee organisations have not been involved in practical projects in any of The Nordic Countries. Employer organisations have prioritised transport supply, public transport services and an efficient road network.

The mode used in commuting is usually considered to be a private consideration and employers are not supposed to play an active role. Most businesses take no initiative by themselves, but respond to requests from outside. Usually the Human Resources Department will be the contact point. While the estate manager takes care of car parking, human resources looks after company cars, sports club (e.g. interest in cycling) etc.

In Sweden, some individual employers have been dealing with Mobility Management actions. Schenker Consulting and Astra Zeneca in Mölndal have been involved with their employees travel. Det naturliga steget (The Natural Step) is an international non-profit organisation working also for sustainable development in commuting. In Denmark companies have involved in Mobility Management through the Copenhagen Pendlerkontor project. In Norway the SMART project has also activated a few companies, e.g. Siemens. In Finland companies have not carried out any large projects on Mobility Management issues but some examples on green commuter plans exist from the 1990's. Campaigns, especially on cycling to work, have been carried out individually by several companies. 


\section{Policy Instruments}

This chapter analyses the current state of the legal and policy framework for Mobility Management in The Nordic Countries. Many national and local regulations and guidelines affect commuter transport, especially mode choice. Income tax is the key policy instrument at the national level. At the local level instruments mainly relate to physical preconditions, parking supply being accentuated. The following legal and other instruments are examined in detail in this chapter along with their current state in The Nordic Countries. An assessment is also made as to whether there is any pressure to change current policy instruments.

Taxation

- Mileage allowances for car use during business trips

- Company public transport fares

- Car parking at employer's place of business

- Long distance commuter trips

- Company cars, company bikes

Building regulations

- Parking (cars and bikes)

- Social premises (showers, wardrobes)

- Mobility Management approach in building by-laws etc.

E-work

- Working time

- Equipment 


\subsection{Taxation Structure}

\section{Commuter Trips}

All The Nordic Countries have certain annual maximum and minimum levels of commuting costs that are eligible for income tax deductions. Usually the minimum level is not reached if a person lives and commutes within the same region (e.g. a work trip of under $20 \mathrm{~km}$ in one direction). Disabled people are covered by special legislation. The following information describes the situation in 2004. The main sources of information have been the web sites of tax administration. In Sweden the address is www.skatteverket.se, in Denmark www.skat.dk, in Norway www.odin.dep.no and in Finland www.vero.fi. The exchange rates used are from the Bank of Finland web site in November 2004.

In Sweden a general rule is that in order to claim commuting expenses the distance between home and work must be at least $2 \mathrm{~km}$. The deduction applies to the cost one pays for e.g. public transport or single tickets. The annual cost over 7,000 SEK (745 euro) is deductible.

Deductions for car or motorcycle use are based on possibilities to use public transport. To be eligible, the distance between home and work has to be at least $5 \mathrm{~km}$ and one has to gain 2 hours a working day by taking the car instead of public transport. In addition, the car should be used for work trips at least 160 days and 3,000 kilometres every year, irrespective of distance travelled and time saved. If the car is used for work trips less than 160 days but at least 60 days and at least 3,000 kilometres every year, the deduction applies for those days when the car is used for work trips.

The deduction for car use is $16 \mathrm{SEK} / 10 \mathrm{~km}(1,7$ euro) and for motorcycles it is $8 \mathrm{SEK} / 10 \mathrm{~km}(0,85$ euro). There is also an additional deduction for bridge, ferry or road tolls. For those having the car as a fringe benefit, the deduction is $6 \mathrm{SEK} / 10 \mathrm{~km}(0,64$ euro) for diesel and 9 $\mathrm{SEK} / 10 \mathrm{~km}(0,96$ euro) for other fuels (e.g. petrol).

If a moped is used for trips between home and work the deduction is 4 $\mathrm{SEK} / 10 \mathrm{~km}(0,43$ euro). If a moped is used for a part of the distance, the deduction is given for that part. A deduction for bicycle use (250 $\mathrm{SEK} / 26,6$ euro a year) applies even if the bike has been only used occasionally when going to and from work.

In Denmark the system is based on mileage travelled per day. Limits for deductible costs are as follows:

Up to $24 \mathrm{~km}$ per day 25-100 km per day over $100 \mathrm{~km}$ per day no deduction

$1.62 \mathrm{DKK} / \mathrm{km}$ (0.22 euro)

$0.81 \mathrm{DKK} / \mathrm{km}$ ( 0.11 euro) 
Persons who have a total annual income of less than 218,400 DKK (29,000 euro) can claim $25 \%$ more. Special benefits also apply in remote areas. The deduction is based solely on the distance travelled.

In Norway a tax break is given for commuter trips when travel costs exceed 9,200 $\mathrm{NKr}$ (1,136 euro) a year.

Up to $35,000 \mathrm{~km}, 1.40 \mathrm{NKr} / \mathrm{km}(0,17$ euro $)$ as standard compensation is paid. For every kilometre exceeding 35,000 km, $0.7 \mathrm{NKr}(0,09$ euro) in compensation is paid. This is an overall standard, regardless of transport mode and real costs.

Reimbursements for ferry, road and toll costs are also made. To be eligible for these, the real costs have to exceed 3,300 NKr/ year (407 euro).

In Finland the system is based on the most economic transport mode available. Public transport, thus, at least in principle, is favoured when compensating commuting expenses. The deductions are dependent mainly on the assumed cost of public transport. Car use is justified (and compensated according to the cost of car use) only if no other mode is available (i.e. no public transport connection or a minimum 2 hour waiting time during the trip). Reasons for car use have to be specified in the tax declaration.

There is a threshold minimum of $500 € /$ year before the deduction takes effect. The maximum deduction for commuting expenses is 4,700 $€ /$ year.

\section{Mileage Allowance for Business Trips}

All The Nordic Countries apply quite similar systems in providing mileage allowances when an employee uses his/her own privately owned vehicle for business related travel. Comparison of these costs is difficult because the real benefit for a particular employee is dependent on several other factors (gasoline tax, income tax level etc.).

In principle it is up to the employee to decide which travel mode to use. Some public sector employers though limit private car usage and favour "the cheapest possible" which usually means public transport.

If an employee uses his or her privately owned vehicle for business trips, the employer can pay him or her an allowance according to the mileage travelled. The maximum tax-free allowance per kilometre by different transport mode that can be paid to an employee is defined every year by tax authorities. Further tax exemptions are possible due to the number of accompanied persons, who has title to the car etc. The tax-free value is set in all The Nordic Countries for cars, mopeds and bicycles. Bicycle use may also be compensated on a daily basis in addition to the mileage rate.

Any out-of-pocket parking fees or road tolls paid during business trips can be reimbursed in full. 
Sweden. The mileage allowance for private car use for business purposes is $16 \mathrm{SEK} / 10 \mathrm{~km}$ (1,7 euro).

Denmark The mileage allowance for using a car or motorbike is 2.98 DKK $/ \mathrm{km}(0.40$ euro $/ \mathrm{km})$ up to a maximum of $20,000 \mathrm{~km}$ per year. For each additional $\mathrm{km}$ above this limit, the allowance is 1.62 DKK $(0.22$ euro)

For the use of one's own cycle or a moped the mileage allowance is 0.40 $\mathrm{DKK} / \mathrm{km}(0.05$ euro)

Norway To be eligible for tax compensation employees can normally use their own car for business trips up to $6,000 \mathrm{~km}$ per year. The compensation is then $3 \mathrm{NKr} / \mathrm{km}(0,37$ euro). If the mileage exceeds $9,000 \mathrm{~km}$ per year the payment per kilometre over the limit is reduced to $2,40 \mathrm{NKr} / \mathrm{km}$ ( 0,3 euro).

When an employee uses his/her own car for a business trip and takes along additional colleagues, the compensation is $0,5 \mathrm{NKr} / \mathrm{km}(0,06$ euro) per passenger.

Finland If an employee uses his/her own car for business travel, the employer pays up to 0,38 euro $/ \mathrm{km}$. For every additional passenger travelling a 0,01 euro/km extra fee is paid. For other means of transport (moped, bicycle etc.) the compensation is 0,08 euro $/ \mathrm{km}$.

If an employee eligible for limited car benefits (i.e. pays fuels $\mathrm{him} /$ herself) uses the car for business travel he/she is entitled to an allowance of 0,09 euro $/ \mathrm{km}$.

If a person uses public transport for business trips he/she is always eligible to be compensated fully for the ticket price. A person may also hold a personal self-paid seasonal public transport ticket that he/she may also use for business purposes (going to meetings etc.) and thus there is no extra cost for using it for business travel as well. It is a bit unclear how electronic tickets (smart-cards) should be handled on business trips. A person may pay his/her business trip by a prepaid value ticket but will not get a receipt and thus no compensation from employer. An alternative is to buy a single ticket that is usually more expensive.

\section{Company Cars}

It depends on the employment arrangements made as to whether an employee receives a company car benefit or not. Usually it is restricted to those either with a high status in the company or doing a lot of business travel. Practices vary a lot. Quite often people calculate that it is not financially advantageous to have a company car. The main advantage of having one is the assumed ease of upkeep, repairs, insurance etc.

Company cars are provided according to many concepts, with both limited and unlimited benefits. Limited means that the company pays all costs excluding gasoline. Unlimited means that the company pays all expenses including running costs. 
If one has the possibility to use a car paid by the employer for private purposes this is regarded as extra income and a tax liability. The tax rate is progressive, dependent on the value of the car. There are also examples of when the taxable value depends on the environmental performance of the vehicle.

In Sweden the tax imposed on company cars as a fringe benefit is divided into a fixed and flexible part. The fixed part is a function of the base rate, government loan rate and purchase price.

In detail, the legislation sets down the following policies. For electric or hybrid cars an adjustment is made to $60 \%$ of the tax liability of fringe benefits for the nearest comparable car that is not eligible for the environmentally adjusted technique. Alcoholic fuel or other gas fuel cars (other than gasoline) are adjusted to $80 \%$. The reduction must not exceed $16,000 \mathrm{SEK} /$ year (1,975 euro) for the former and $8000 \mathrm{SEK} /$ year (899 euro) for the latter. New policies were launched in January 2002 and extend to the year 2008 .

The flexible part depends on who pays for the fuel. If the employee does, there will be no tax liability for the fringe benefits. Instead, the travel expenses will be borne by the employer for work trips.

If the employer pays for the fuel, the employee is taxed for the fuel used for private trips at $120 \%$ of the market price. The employee must also maintain a driving journal. It must contain the date of the work trip, meter reading before and after the trip, reason for the trip, who was visited and the time.

In Denmark the taxation level of a company car is:

- $25 \%$ of the value of the car (purchase price) up to $300,000 \mathrm{DKK}$ (40,000 euro)

- $20 \%$ of the value of the car that exceeds 300,000 DKK

The car is always considered to be worth at least 160,000 DKK $(22,000$ euro). This means that the annual extra taxation will be at least 40,000 DKK (5,000 euro). The maximum marginal taxation rate is in average $63 \%$. A company car thus will typically cost the employee at least 25,000 DKK (3,400 euro) annually.

The taxable benefit in Norway depends on the price per kilometre. It is a function of the value of the car, with cheaper ones favoured. The minimum price per kilometre is $2,88 \mathrm{NKr} / \mathrm{km}(0,36$ euro) and maximum 7.NKr $/ \mathrm{km}(0,86$ euro).

In Norway this system is most probably now being changed, with lower tax-levels. An advisor group has proposed that the tax level should be reduced, and also that commuter trips with company cars should not be considered as a taxable benefit. (www.bilnorge.no/firmabil)

In Finland the taxable value of a company car is determined by the model and age of the vehicle. The Tax Administration valuates company 
cars not only by their resale values but also by their estimated running costs. The taxable value of a company car can be increased in case the employer drives less than $18,000 \mathrm{~km} /$ year and reduced if driven more than $30,000 \mathrm{~km} /$ year.

\section{Company Paid Public Transport Ticket}

In all The Nordic Countries the taxable level of a company paid public transport fare is $100 \%$. Changes to the situation are under active discussion in Finland and are also ongoing at a high political level in other The Nordic Countries.

The main arguments against reducing the taxable value stem from social equity concerns, the ticketing systems and the tariff regions. In Finland, for example, the Ministry of Finance is against the idea because all employees should have the same possibility for and advantage of the fringe benefits offered by the employer. The advantage derived from a partly free public transport ticket varies greatly depending on where one lives. The longer the trip and the higher the ticket price the bigger the advantage is for a single person. The tax administration also opposes changes to the present practise.

In principle, free car parking and company cars could also be discussed from the point of view of social equity. These benefits are not available to everyone.

In Denmark it has been settled that an employer can pay a season ticket (periodekort) for public transport without other tax consequences for the employee, but the employee cannot at the same time claim the usual deductible value of his commuter trips. Moreover, if the employer does not want to pay, the employee can pay for it out of his own salary, and thus save a considerable amount due to taxation. This is still on the condition that nothing is deducted on the tax bill for commuting. If, however, the employee extensively uses the season ticket for private purposes, this part can be taxed. Sporadic use is accepted though. (www.erhverv. toldskat.dk)

In 2004 a working group was set up to analyse how the attractiveness and market share of public transport could be increased in Finland and especially in the Helsinki region. One of the main recommendations of the working group concerned the taxation of employer-paid tickets. The pressure to change the taxation value comes from the current Government program where it is stated that "it should be analysed how the taxation structure of employer paid tickets could be changed". The group made the following calculations (table 2): 
Table 2. Calculation on effects of changing taxation value of employer-paid tickets.

\begin{tabular}{|c|c|}
\hline Proposal & $\begin{array}{l}75 \% \text { of price paid by employee, } 25 \% \text { by employer. } \\
\text { Taxation value covers the proportion paid by the employee. } \\
25 \% \text { is estimated to cover trips related to business meetings } \\
\text { etc. }\end{array}$ \\
\hline Costs & decrease of tax revenues $6 \mathrm{M} €$ \\
\hline Benefits & increased ticket sales, social benefits $23 \mathrm{M} €$ \\
\hline Modal shift & $\begin{array}{l}\text { In capital region: } 1,5-2,0 \% \text { increase in public transport use } \\
\text { (assuming that } 50 \% \text { of work force has the perquisite) }\end{array}$ \\
\hline
\end{tabular}

Liikenne- ja viestintäministeriö 2004

If the taxation value is to be changed modifications to the Income Tax Act are needed. Primarily the question relates to public transport policy. There is strong political support for the change and the new system could be introduced in 2005 .

\section{Welfare Incitements}

All benefits provided by the employer are in principle to be regarded as extra income and are liable to taxation. Within certain limits some welfare provisions are accepted without taxation. If physical exercise can be defined as "reasonable welfare-measures", this will not count as a taxable benefit for the employees. To be "reasonable", these measures have to be offered to most of the employees, and the goals must be "creating good working environment" and "increasing the well-being" at work. Such measures can be:

- exercise rooms

- welfare trips (skiing trips, cycling-tours etc.)

- supporting local sport activities such as football, table-tennis tournaments etc.

If these measures involve direct payment to employees or payment of equipment for training (including bicycles) this will automatically count as taxable income.

A big part of the employees who take part in the Danish bicycle to work campaign get the participation fee 20 DKK (2.70 euro) paid by the employer. No taxation problems have occurred from this.

Some employers in Norway have tried to increase the level of compensation for those who use a bicycle during business trips. So far the central government has not been willing to accept this because it can be seen as a step towards having standard compensation for bicycle-use. Some employers have also tried to invest in bicycles that employees could buy from the company at a reduced price. These bikes were painted with company colours and logo, and the company stated the reasons for this to be: 1) a welfare/health effort for employees, and 2) a way of mar- 
keting the company. In spite of these arguments, the employees had to pay tax from this benefit.

In Finland so called "competence improving activities" have been included in the occupational health legislation since the beginning of the 1990's and thus have a statutory position. Activities aimed at improving employee working capacity are mainly directed to the elderly. In 2004 Finland established a "motion ticket" as a new fringe benefit. Employers can thus support staff exercise (200 €/year/employee) with no tax consequences. Exercise cannot, however, cover buying a bicycle for commuting purposes.

\section{Car-sharing}

If an employer is a member of a car-sharing company and allows employees the possibility to drive the car-club cars there are no tax consequences if the employee pays the running costs. If, on the other hand, the employer also pays the running costs (costs which car-club operator has set based on the price of gasoline etc.) there may be a limit for a nontaxable benefit. In Finland this is viewed as "casual driving" in the tax rules and the limit is some $1,500 \mathrm{~km} /$ month on average (Laine 2004).

\section{Carpooling}

If people pay for getting a lift in a colleague's car (carpooling) it is considered as commercial transport and is thus taxable. No licence for passenger transport is needed if the principles of reciprocity are followed. Following up on these rules by tax authorities is quite difficult.

\section{Transportation Organized by Employer}

Shared transport for employees travel to work is considered as tax-free in e.g. Finland. It is possible thus for an employer to provide a staff bus for commuting purposes. Due to the rapid increase in car ownership though this advantage is rarely used now. In Denmark the employers operated bus service for employees is considered a taxable benefit.

\section{Parking as a Fringe Benefit}

Usually, reserved parking for employees is not regarded as a taxable benefit regardless if the employer rents or owns them.

Sweden is an exception to this. According to the Swedish National Tax Board, a person using his/her car less than 60 days or 3,000 kilometres a year for work purposes has to pay tax for the benefits received from free parking. Those who drive between 60 and 160 days a year pay tax 
according to the share spent for private driving. A person driving more than 3,000 kilometres and 160 days is not subject to tax.

Free in or outdoor parking at the workplace for company cars is not considered as a fringe benefit for tax purposes. If, on the other hand, it is an employee owned car, free parking at the workplace is in principle a taxable benefit. Such a benefit may be fully or half exempt from taxation if the car is regularly used for work purposes. Today many companies offer free parking for their employees even if the parking fee should comprise the tax imposed on fringe benefits.

\subsection{National and Local Planning and Building Regulations}

Sweden The Swedish National Building Law (Plan och bygglagen PBL) specifies that an appropriate area for parking and loading of vehicles, of a legitimate and reasonable size, needs to be provided on or near to the property. Municipalities set parking standards accordingly.

The City of Stockholm has no general parking standard. Rather, parking standards are site-specific dependent on location, type of activity and function. The standard applied for the inner city is 0,48 parking spaces / flat and 5 spaces / 1,000 sq m offices. At the lower end, an example is the local development area of Hammarby Sjöstad with 0,45 parking spaces per flat $-0,25$ garage, 0,1 for visitors and 0,1 on street.

Requirements concerning provision of bicycle parking and showers depend on the company's areas of activity. These demands are not regulated by the PBL.

In Copenhagen, Denmark a minimum of 1 parking space per $100 \mathrm{~m}^{2}$ housing area is required. In Ørestaden a maximum limit is however set (1 parking space per $200 \mathrm{~m}^{2}$ and 1 parking space per $100 \mathrm{~m}^{2}$, depending on the location in the area).

Usually there are no special requirements for bicycle parking but exceptions do exist. The Municipality of Odense, for example, has in a specific case (the establishment of a cinema) required a certain amount of bicycle parking spots to be built. The municipality is planning to use such requirements more.

In Norway the provision of parking is regulated by minimum, maximum and absolute norms. In Oslo, parking space regulations are dependent on the local area in the city and on the applicable residential, public and industrial building codes.

New parking norms for residences in Oslo are valid from 2002 onward. In general, they have reduced the minimum norms for car parking and have also established minimum ones for bicycle parking The local government in Oslo is currently working on establishing new parking norms for public and industrial buildings. It appears that they will be a bit 
more restrictive, relying more on maximum norms and also reducing the minimum norms. Minimum norms for bicycle parking will also be given.

In Finland the minimum level of parking places per employee is set in local building codes. Only for the city centre of Helsinki is the maximum value for different functions applied. For working places in the inner city the limit is a maximum of 1 parking place for 500 floor square meters and a bit further away from the central business district the value is 1 parking place per 350 floor square meters. In other parts of Helsinki minimum values or combinations of both maximum and minimum norms are applied.

The first municipality in Finland to mention bicycle parking in the municipal building code was Kangasala (23,000 inhabitants) in 1996. Bicycle parking is to be provided as follows: 1 space for 50 square meters in shopping, office and public areas, 2 spaces for each dwelling, and 1 space for 3 employees in industrial areas. At least half of the bicycle places should be sheltered. Bicycle parking has been included in building codes also in some other smaller towns.

Dressing rooms and showers are not included in building codes unless the type of the work creates a demand for such installations (physically exhausting work, need for hygienic conditions, or dealing with noxious fumes, caustic materials etc.). Physical activity during commuting is not considered as reason to provide special social premises in working places. The situation is the same in all The Nordic Countries. Usually new office buildings have better social premises that give more possibilities for cycling or roller-skating to work.

\subsection{E-Work}

In Sweden, according to the Income Tax Act, it is possible to buy an employee a subsidized computer without it being a tax liability as a fringe benefit. Other ancillary equipment for the home such as chairs or writing desks do not however enjoy the same tax relief.

Teleworking (e.g. while travelling) may be counted as working time although there are no regulations in the legislation controlling it. That possibility, however, depends on the employment contract. Generally, it is easier for employees in the private sector to take advantage of this benefit

According to the National Social Insurance Board, in the event of an injury the employer has the same responsibility as if the injury had occurred at the office.

In Denmark the employer can pay for the employee's computer equipment without tax consequences. This is also true if the computer is used for private purposes. The employer can also without tax consequen- 
ces pay for a data connection at the employee's home, if some requirements are fulfilled.

In Norway rules for employees working at home are defined in the Law of Work Protection and Work Environment. If employers want to encourage and arrange mobile E-work, they have to make written agreements with the employee. This agreement has to cover aspects such as type of work, working hours, equipment used, employees' availability, professional secrecy etc. If employees work during their commuter trip and wish it to be counted as working hours, this too has to be regulated in an agreement between the parties. Normally, though, this type of work is not accepted as working hours. If an employee has to invest in data equipment to work at home, tax compensation can be given. Employers often support this kind of investments directly.

Also in Finland E-work is always based on a voluntary agreement between the employer and employee. Agreements include data connections, telephone costs, working hours and other practical details. The employee can obtain a tax deduction based on the use of his/her home for E-work. These guidelines are established by the tax administration.

The employer can buy the employee a lap-top / computer, data connections and even a chair for working purposes without any tax consequences as long as the employer is the owner of the equipment. The owner of the equipment is responsible for the insurance coverage.

Trade unions have in principle a positive attitude towards e-work if it is done on voluntary basis and agreements are made between the employer and employees. Working while travelling can be accepted as working hours but the employee should make sure that employer accepts this.

\subsection{Guidelines}

Some national planning agencies have recommendations on Mobility Management and general knowledge about the subject is increasing.

In Sweden a new planning handbook, TRAST, was published in 2004 by the National Road Administration (Vägverket) and the Association for Municipalities (Svenska kommunförbundet). TRAST is the acronym for the process described the handbook - Trafik för en attraktiv stad. Mobility Management is a concept mentioned in TRAST in connection with handling travel demand issues. The aim is to give guidance to planners and decisions-makers about the local transport strategy process and to better integrate transport issues with town planning. (www.vv.se/vgutrast)

The Danish Association for Municipalities (Kommunernes Landsforening) has produced a leaflet about "pendlerplaner" (commuter plans) and the consultancy Tetraplan is in the process of developing a web-based questionnaire to be used for making these plans. The questionnaire will 
be available from the website. The web-tool will be available by the end of 2004.

The Norwegian National Road Authorities and GRIP (the Norwegian Foundation for Sustainable Production and Consumption) have cooperated in developing a practical guide for businesses wanting to meet their transport challenges with various forms of Mobility Management efforts. This guide is to be finalised in November 2004.

In Finland The Ministry of Transport and Communications published in 2002 a report on Mobility Management containing measures that the government, local authorities, companies and other organisations should take in order to promote Mobility Management. More information on this report on page 75. The Ministry of Environment published in 2003 a handbook on transport issues in community planning. The aim of the book is to give a general view of the role of transport in community development for planners, politics and authorities. The book concentrates on the issues that are under the purview of municipalities and transport authorities. Mobility Management is handled in the book as a way to activate new counterparts to promote sustainable transport through a set of "soft measures". (Ympäristöministeriö 2003) 


\section{Mobility Management Actions Related to Commuting}

The aim of the case study analysis is to present a few effective and practical projects related to Mobility Management for commuting. The projects selected encompass quite large applications, have already been evaluated, and cover a variety of tools and transport modes. The case study analysis is structured along the following lines:

- Initiators

- Organisation

- Finance, resources

- Aims

- Duration

- Project components

- Evaluation of results compared to aims

- Lessons learned

\subsection{Sweden}

\section{Vision Lundby}

\section{Background, Aims and Context}

A large redevelopment currently underway in a former inner-city harbour area - the Lundby district in Gothenburg - aims to realise a combined housing, education and business area. The number of people working and living in Lundby will be doubled to at least 50,000 (2022). Underlying problems in Gothenburg's road transport system acted as a catalyst to the project's implementation. Congestion is frequent due to capacity problems on the three existing crossings over the Göta River.

Broad political support to solve the cross-river problems gave a kickstart to the Lundby project. The idea arose during 1999, as an outcome of an eco-car project that was implemented in the city. The idea, due to the site's appropriateness, was to use Lundby as a testing ground for future full-scale introduction of sustainable transport solutions in Gothenburg. (Sundell 2003) After gaining economic support from the Traffic Committee, Lundby was chosen due to the possibilities of introducing the Mobility Management solutions early on in the planning process. 
The objective is to draw attention to the choices available, to develop and test transport alternatives - all in order to help travellers to be pro-active in their modal choice. The general objective has been grouped into a number of perspectives and actions directed towards individuals as well as companies. An important aim is to achieve a wide collaboration. Favourable relations between the Traffic Committee and Traffic and Public Transport Authority provided a solid base for the initiatives.

Finance

Vision Lundby is financed with a budget of 8-9 million SEK/year (760 $000-860000$ euro/year). Although most of the funding is from the Traffic and Public Transport Authority and EU, financial support has also been received from other bodies for some sub-projects. Two European funded projects (CIVITAS and TARGET) have provided possibilities to extend the activity, employ a project team and open the mobility centre. A KLIMP (Climate Investment Program) application has been submitted recently in order to further enhance direct marketing activities.

European funding will end by the end of 2005 and this will have implications for the future of Vision Lundby. The establishment of the ITS/Mobility Management Department at the Traffic and Public Transport Authority means that Mobility Management activities will receive continued support in the future within the authority's organisation. Vision Lundby will remain as a pilot project although its scope will broaden out throughout the entire City of Gothenburg. The future organisation will change in some respects but the support and integration within the ITS/Mobility Management Department will increase. The focus on households and companies will remain. Actions directed to companies will increase. (Sundell 2004)

\section{Organisation - Key Players - Working Process}

Vision Lundby comprises a steering committee and a project group. The steering committee (the key players) consists of the project manager and representatives from the following agencies:

- The Traffic and Public Transport Authority (initiatives, driving force)

- City Planning Authority (planning)

- Norra Älvstranden utveckling AB (development company, landowner, contacts with companies)

- Regional Public Transport Authority (public transport)

- District Administration of Lundby (local area, link to the inhabitants)

- Swedish National Road Administration (financing, follow-up on the projects)

Other representatives from the administrations form the project group. The personnel consist of seven people, half full-time. They have various 
backgrounds (e.g. educationalists, environmental scientists, economists) and deal with the seven priority issues of:

- Vision Lundby and Lundby Mobility Centre

- Smarter communication for companies

- Smarter communication for the individual

- Freight collaboration

- Car-sharing for companies and individuals

- Children and Youth

- Cycling

The Lundby team promotes and illustrates best practice in smart transport solutions and acts as an intermediary in contacting suitable companies that provide solutions. (www.visionlundby.goteborg.se) Contacts with companies and inhabitants in the area have been made in numerous ways during the years. In 2001, for example, the work focused on establishing and expanding contact networks, on knowledge building and establishing information channels (such as a website and newsletter), on a number of actions (e.g. the Lundby Card, freight collaboration, and car sharing) and on approaching companies.

Vision Lundby expanded in 2002 when three European collaborative projects were activated. A number of new people were recruited and interest for car-sharing and coordination of goods transport increased. The Mobility Centre opened in 2003.

Action

Vision Lundby is a continuous, collaborative project for the development and acquisition of knowledge about sustainable traffic and transport solutions. It will reduce environmental impacts and meet accessibility and safety requirements. The Lundby Mobility Centre forms the core - a service centre for those companies and individuals in Lundby who require support and advice with regard to developing the efficient and sustainable transportation of people and goods. Several actions have been directed to companies and individuals (table 3 ).

Table 3. A list of some actions carried out by Lundby Mobility Centre.

\begin{tabular}{|l|l|}
\hline $\begin{array}{l}\text { For companies } \\
\text { and staff }\end{array}$ & For individuals \\
\hline $\begin{array}{l}\text { Public transport - e.g. a new trunk bus } \\
\text { line }\end{array}$ & Expanded public transport facilities \\
\hline Company bicycles & Cycling \\
\hline Clean Vehicles & Exhaust emission measurement \\
\hline Car-sharing for companies & Car-sharing \\
\hline Freight collaboration & 'Scrap that car' campaign \\
\hline Environmental transport guidelines & Children and youth \\
\hline
\end{tabular}


The main counterparts in the companies are the personnel managers or MDs. Subsequently, other heads/levels in the organisation become involved, depending on where the responsibilities for vehicle management or trip planning are. Companies located in the area that have a environmental management system are listed. (Lindau 2004)

\section{Communication / Information}

Vision Lundby, in itself, is an information project. In general, people consider the provided information as easy to understand. A large amount of brochures and leaflets have been produced (picture 1). A website is accessible providing helpful information about the project in general and its numerous sub-projects and actions. The Lundby Map (paper format) provides information about the project and a map, links, and detailed contact information about alternative transport modes.

Picture 1. Example of Vision Lundby information

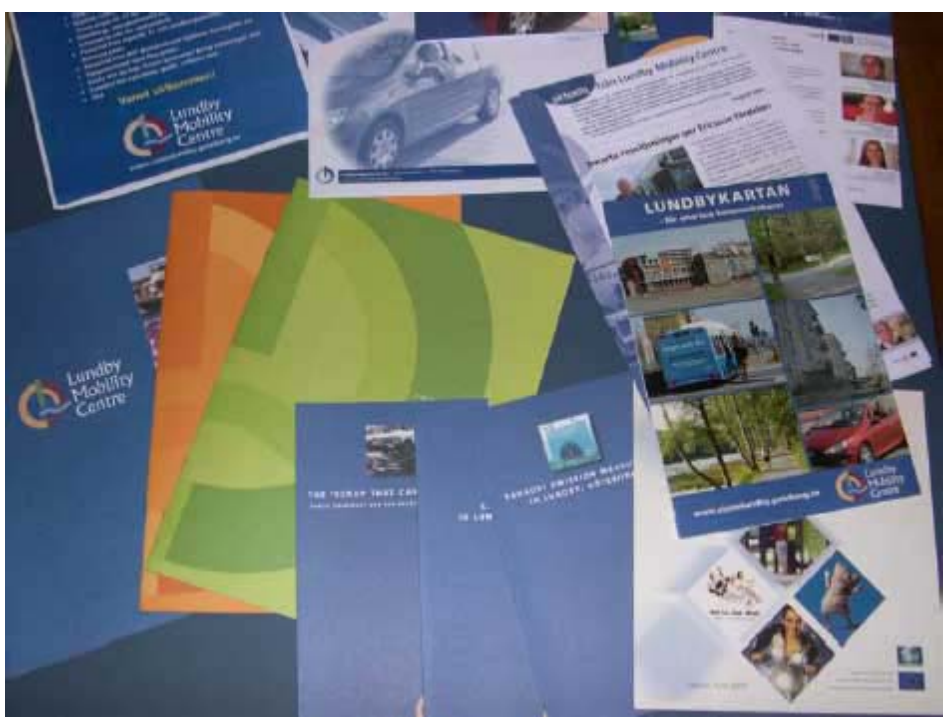

Measuring the Effects

Annual questionnaires aimed at measuring the effects have been carried out during 2002 and 2003. It is still too early to see obvious tendencies from the results but it is clear that information about Vision Lundby's fields of work had reached its recipients The annual evaluation continues in a new questionnaire to be issued in November 2004. Evaluation of subprojects is also carried out by telephone interviews. An overall evaluation plan is set up in accordance with the MOST model. The plan clearly delineates objectives, targets groups and the methods utilised. MOST plans are set up for every single project. During 2005 the work completed so far will be reported. Requirements concerning evaluation vary between the EU funded projects. Permanent changes are in focus due to the fullscale implementation of Mobility Management measures in all of 
Gothenburg. As the project was only launched recently, with a strong long-term future focus, comments concerning results of permanent changes are too early to state. (Sundell 2004)

\section{Important Experiences}

When speaking to people responsible for the Vision Lundby project, a number of facts were pointed out, e.g.:

- The driving forces are most of all based upon individuals.

- Difficulties have arisen about the initial aim to introduce Mobility Management perspective early in the planning process, especially concerning collaboration and cooperation between different departments within the municipality. Getting land use plans to handle Mobility Management issues is hard, according to the experiences. A focal point is needed to introduce the right actions at the right time.

- Actions towards private companies constitute an important factor for success. Health aspects are of great interest among the companies. Service companies tend to be easier to work with, often depending on their access and experience of web-related services. Especially companies with environmental management systems are conscious about Mobility Management activities.

- When the projects have been in action for some time, the fight for funding becomes crucial This fight is a problem due to the desired long-term perspective.

- A large number of smaller adjustments in the law are required in order to give the Mobility Management issues a more powerful position in the legislation e.g. "Plan och bygglagen" have to be more powerful tool in terms of parking solutions.

- Public transport improvements make Lundby attractive in terms of property development. The bus link is a great success. The initial fears from companies of lack of accessibility across Göta River have diminished and Lundby is an attractive site. 


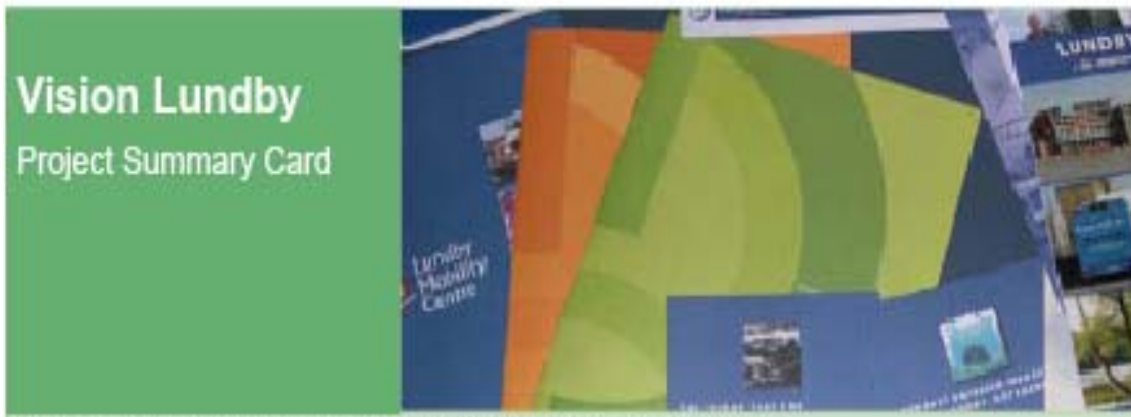

Project duration/period, financiers and partners, budget

Launched in 2000 and ongoing and is run in co-operation with the District Administration of Lundby, the City Planning Authority, Västtrafik (Regional Public Transport Authority), Norra Älvstranden Utveckling AB and the western division of the Swedish National Road Administration. The main financiers are the Traffic and Public Transport Authority and EU with some funding support from other partners for sub-projects. Financing about $760000-860000$ euro/year.

\section{Project aims}

The objective is to draw attention to the choices available and to develop and test transport alternatives in order to help travellers to be pro-active in their modal choice. Vision Lundby tests these alternatives and participates in projects aimed at encouraging changes in travel behaviour. Lundby is a test site for the future full-scale introduction of sustainable transport solutions in Gothenburg.

Actions taken

Actions towards companies and individuals, e.g. improved public transport, bicycle projects, clean vehicles, car-sharing for companies, freight collaboration, exhaust emission measurement, 'Scrap that car' campaign. Lundby Mobility Centre forms the core.

\section{Evaluation methods}

A questionnaire has been distributed to work places and households each autumn since 2002. Evaluation of sub-projects is also carried out by telephone interviews. An overall evaluation plan has been developed in accordance with the MOST model.

\section{Results:}

The outcome of the evaluation in 2002 pointed out that the recipients had just a little knowledge about the project but were interested about alternatives to the car. In 2004, the results demonstrated that it is too early to see obvious tendencies but it was clear that information about Vision Lundby's fields of work had reached its recipients.

\section{Learnings/experiences}

Some examples: Public transport improvements make Lundby attractive. Actions towards private companies constitute an important fact for success. Companies with environmental management systems are aware of mobility management activities. A large number of smaller adjustments in the law are required in order to give mobility management issues a more powerful position. 


\section{LundaMaTs}

\section{Background, Aims and Context}

Political initiatives were taken in 1995 to set up an environmentally sensitive transport plan. During the Municipality of Lund's Municipal Comprehensive Plan and Agenda 21 process, a need arose for a concrete plan of action to reduce emissions and other negative impacts from the transport system. The Municipal Council approved the LundaMaTs study in 1997. Aims and objectives were set concerning reduction of emissions, better air quality, noise reduction, improved recycling and more effective land use planning. The results of the LundaMaTs study indicated that there is much the city can do in this respect but that, if the objectives that have been set are to be achieved, appropriate actions are needed not only at a regional but also at a national level.

\section{Finance}

To enable work with the LundaMaTs system, the Municipality of Lund received a special grant for environmental improvements from the Swedish Department of the Environment. A LIP (Local Investment Program) application was handed in 1997. In total, 300 million SEK (33 million euro) are to be invested since 1998 including state and local subsidies. Of this investment, the Lund Link constitutes the largest amount, 180 million SEK (20 million euro). (Eriksson 2004)

LIP covers two periods, 1998-2001 and 2002-2004. A KLIMP (Climate Investment Program) application has been submitted in 2004, which gives possibilities for further work, in addition to the ordinary activity's grant. The future for LundaMaTs is secured in the municipal budget. However the resources are not at the same level as initially. A decision of May 2004 gives the Technical Committee 1,5 million SEK $(170,000$ euro) extra in order to work with behavioural influence measures.

Organisation - Key Players - Working Process

The Municipal Council approved the LundaMaTs study and its action programme. A project organization set up by the Technical Services Department and the project team had representatives from the Technical Services Committee, Planning and Building Committee and others actors, both within and outside the municipality.

In 2005, a new unit, Transport and Environment, will be established as a part of the Technical and Services Department. With nearly all of LundaMaTs actions already been integrated in the department's regular activities, Mobility Management will be given an official platform as well. (Elmkvist 2004)

The working process includes a great number of measures involving numerous actors, individuals as well as companies. The Mobility Centre staff comprises eight people with various backgrounds (e.g. behavioural 
scientists, environmental scientists, information technologists, human geographers, civil engineers) dealing with the smart road user, commuter trips, carpooling, Eco-driving, eco-cars, car use reduction, land use planning and information. They are working in accordance with their guiding principles: diversity, dialogue, individual adjusted information and test in practice.

\section{Actions}

The LundaMaTs study identified five major reforms: town and country planning, the bicycle friendly town, extended public transportation, environmentally friendly car traffic and commercial and industrial transportation. The reforms were put into practice in four projects, during the period 1998-2001:

- The Lund Link

- The Bike Municipality of Lund

- The Mobility Centre

- Walk or cycle to school.

During 2002-2004, the Mobility Centre and Bicycle Municipality projects are continuing and a new project Environmentally Sound Car Traffic started. A great number of projects varying in size and scope have started within the study framework.

LundaMaTs is focussing on behavioural change actions - to get people to modify their habits through individually based encouragement. Behavioural influence before attitude influence is the catchword. A great number of actions implemented simultaneously makes it difficult to isolate the most effective method, in terms of best practice. The actions are carrots, not sticks, and thereby more promising as new national regulatory instruments. A best practice action is the Test Riders project where car drivers commute with public transport for one month. The results and experiences are very good $-40 \%$ still used public transport after a year.

Campaigns at work places are conducted in cooperation with the company/organisation visited. The aim is to offer companies a variety of measures and help them in carrying out different activities. The success of these actions directed at companies has varied. In general, it is important to disseminate information widely about the actions. Involving the private sector is a time consuming process and Lund will work further on the issue, looking at other Swedish projects.

The Mobility Centre will be extended into 2005 in accordance with a decision from EPA. Some financial support is left, mostly within the land use and transport sub-project. Due to the slow land use planning process, the aim is to continue the work even during 2005. (Elmkvist 2004) 
Communication / Information

Direct marketing and dialogue are strong focuses within the project. The main task is to meet the inhabitants where they are working or living. For example, this is carried out via knocking on doors at homes and working places. The project is well documented. A CD with material and films gives access to important information concerning the project. Campaign material is produced for the sub-projects (picture 2). LundaMaTs is also presented on the municipal website.

\section{Picture 2. Example of LundaMaTs information}

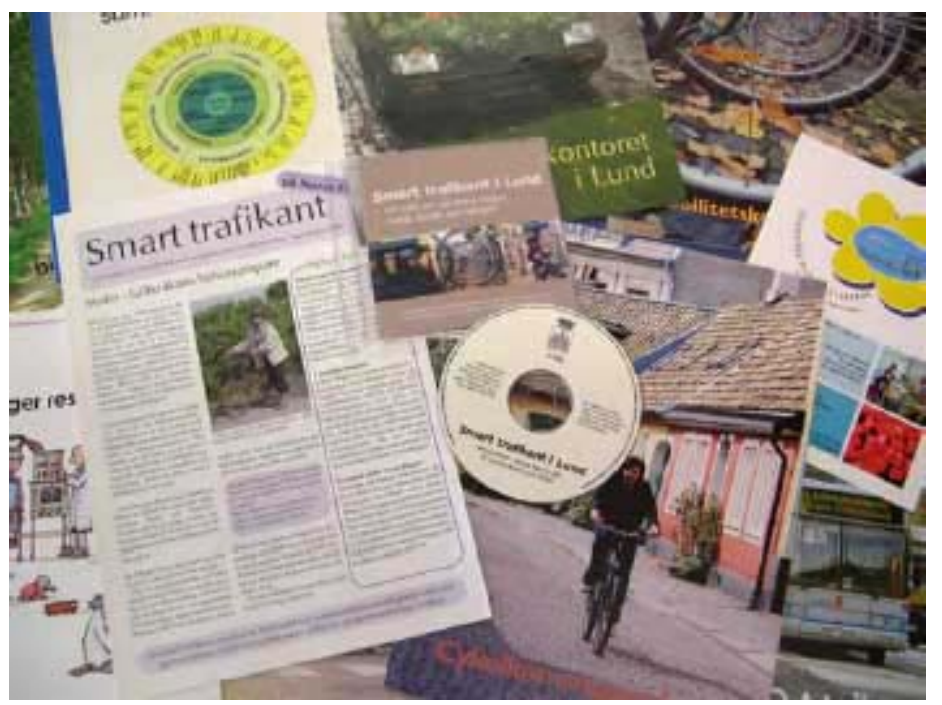

Measuring the Effects

A questionnaire about residents' awareness of LundaMaTs and changes in travelling behaviour was carried out in 2001. The evaluation of LundaMaTs constitutes one case example in the MOST report. The results illustrated great support:

- $90 \%$ state that the investments in sustainable transports are good

- $10 \%$ have changed their travelling behaviour in a positive direction thanks to the activities.

The evaluation shows that soft measures are of the same, or even higher, importance than physical ones (tables 4 and 5). Larger effects are expected, assuming that the investments will continue. Collaboration between public and private partners has developed during the project, and the interest has increased from other partners (e.g. public transport providers) during the project. (Hyllenius 2003). The gain for different actors and target groups are more evident today than at the beginning of the project. The evaluation in 2001 found that the media and special projects served as the main information sources about LundaMaTs among the inhabitants in the city. During spring 2004, a new questionnaire was sent out and the 
results are currently being prepared. (Hyllenius \& Lyborg 2001) The questions are in general the same as year 2001; some changes have been made to account for actual projects implemented during the project period. (Elmkvist 2004)

Table 4. Changed travelling behaviour due to LundaMaTs actions, share of inhabitants

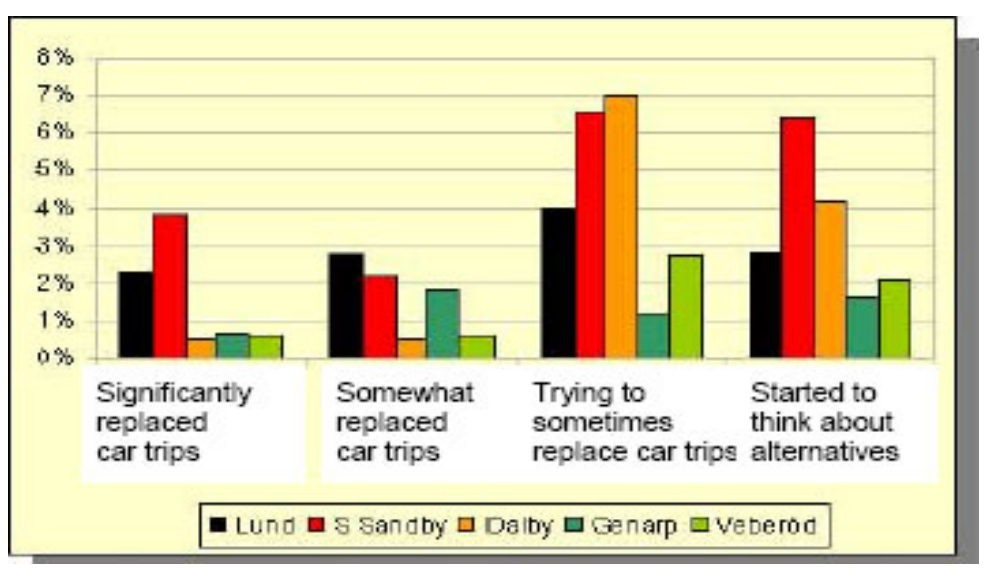

Hyllenius \& Lyborg 2001

Table 5. Effects on car trips due to LundaMaTs actions among the inhabitants in the Municipality

\begin{tabular}{|l|r|r|r|} 
& Bicycle & Public transport & Total sum \\
\hline Million km/year & 2,0 & 1,9 & 3,9 \\
\hline Tons CO/year & 520 & 380 & 900 \\
\hline
\end{tabular}

Hyllenius \& Lyborg 2001

\section{Important Experiences}

When speaking to people responsible for the LundaMaTs project, a number of facts were pointed out, e.g.:

- The massive political support and unity has been the most important factor for success. The project has given prerequisites for setting municipal priorities and a broad knowledge platform.

- Planning is particularly important to achieve long-term effects of the Mobility Management initiatives. An action related to the complexity of integration is to be found within the sub-project land use and planning. A handbook is in production in order to better integrate Mobility Management questions in the planning process.

- PBL has restrictions when integrating the Mobility Management perspective in land use planning. Legislation obstacles are obvious. A powerful tool is needed for Mobility Management questions that are connected to PBA. The current Swedish system is not set up to handle Mobility Management questions in the planning process. The Municipal Comprehensive Plan offers a great opportunity to include planning for car use reductions but extending it to the Detailed 
Development Plan is complex. Even though the Municipality is responsible for local transport planning there are difficulties to regulate developments in the local area when the regional trend is strong, e.g. regional transport is facilitated.

- Tax imposed on fringe benefits. The classic example: tax imposed on fringe benefits on parking places that not are put into practice.

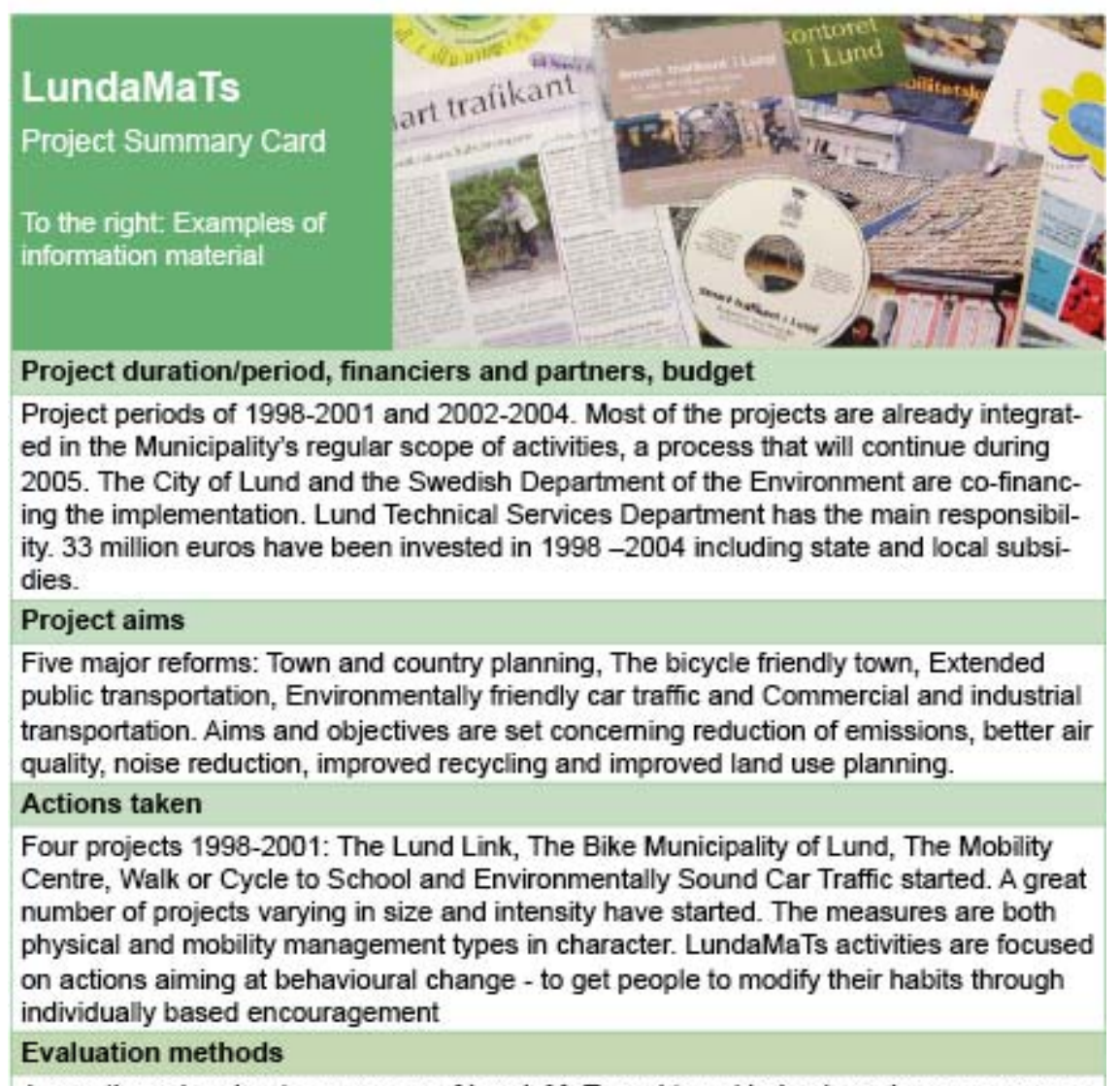

A questionnaire about awareness of LundaMaTs and travel behaviour changes was carried out in 2001. The evaluation of LundaMaTs constitutes one example in MOST-MET. Evaluation is in progress during fall 2004.

Results

The results of the evaluation 2001 illustrated great support, e.g. $90 \%$ state that the investments in sustainable transports are good. $10 \%$ have changed their travelling behaviour in a positive direction thanks to the activities.

Learnings/experiences

The evaluation shows that soft measures are of the same, or even higher, importance as physical ones. The massive political support and unity have been the most important factors for success. 


\subsection{Denmark}

Bike Busters Aarhus

Main Reference:

Aalborg University 2000. Evaluering af CykelBus'ter projektet 19992000. Transport Research Group at Aalborg University.

\section{Starting Phase}

The project Bike Busters shows that it is possible to bring about a significant change in transport behaviour by a combination of carrots (bicycles etc.), information and social control (questionnaires, diaries).

The initiative for Bike Busters came from Aarhus City's Planning Department, with department engineer Jørgen Bunde as the driving force. The aim was to try and see what would happen, if the usual excuses of daily car users for using their car instead of going by bicycle or using the bus system were suddenly eliminated to the greatest possible extent. The reason to act was, on one hand, the well-known negative environmental impact of car use, and, on the other hand, increasing congestion and parking problems in the City of Aarhus. The work associated with a traffic and environment plan for Aarhus served as inspiration to the project.

The project lasted one year for the participants and took place May 1995 to April 1996. The preparation phase with applications etc. lasted over a year, with one of the applications sent in March 1994. The last of a range of research reports was issued in the year 2000.

A secretariat manned with two employees from the City of Aarhus was set up to take care of the contact with the project participants and solve whatever problems might come up. The secretariat published a bimonthly newsletter "Cykel \& Bus'ter" with specific and general information for the participants. The secretariat also planned information meetings and a recreational bicycle excursion for the participants. A massive recruitment campaign was carried out in Aarhus in January and February 1995. The search for participants was published by advertisements in local newspapers and by a flyer (picture 3 ), which was distributed to motorists at the entrance roads to Aarhus Centre in the morning rush hours as well as at major places of work in Aarhus Centre, public libraries and other public institutions. The press also wrote about the campaign and its aims. 
Picture 3. The recruitment folder for Bike Busters.
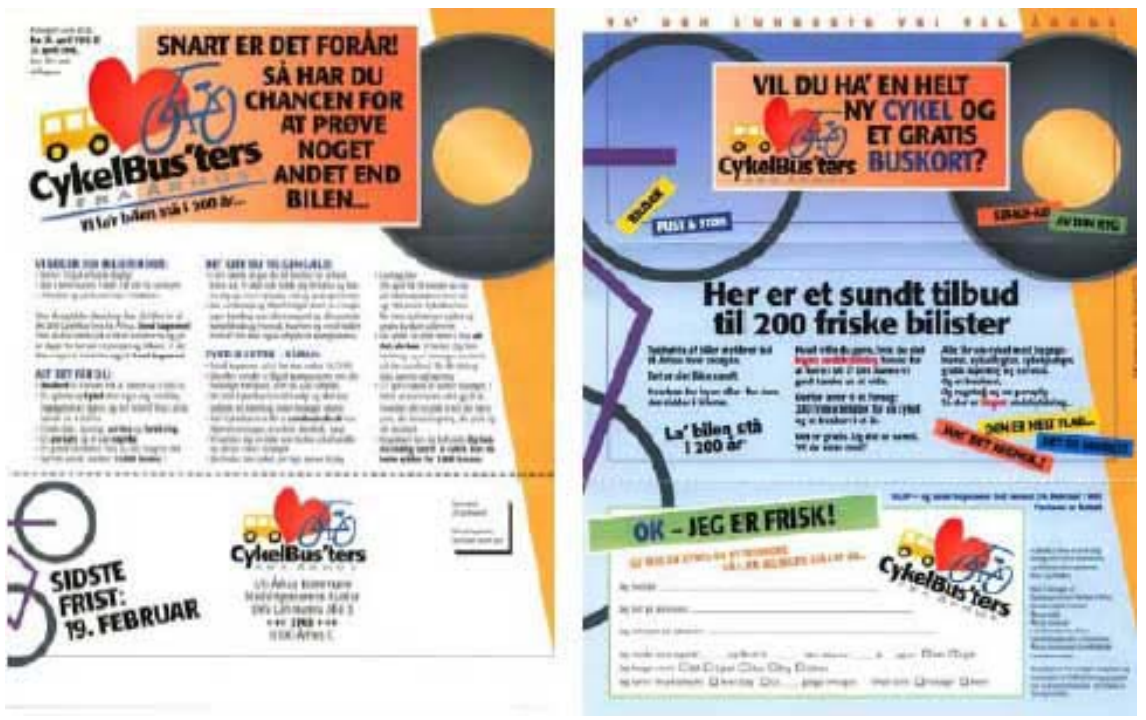

The participants should fulfil the following criteria:

- use the car on a daily basis between home and work

- work and park in the centre of Aarhus

- live in the Municipality of Aarhus at a distance of between 2 and 8 kilometres from the centre.

In return for signing a contract on avoiding car use, participants were offered an almost free bicycle and free bus tickets, as well as: rainwear, bicycle lights, bicycle computer, gloves and some other items with the project logo (umbrella, towel). Basic, free service for the bicycle (service checks and repair of three punctures) was also part of the package. Participants were, finally, admitted to three health checks (measurement of physical fitness, blood pressure, cholesterol, weight) before and during the project.

The contract signed by the participants - besides some more practical issues - stated that they "to the greatest possible extent will leave the car and instead use bicycle or bus for the daily transport". The participants, moreover, committed themselves to reply to questionnaires and transport diaries during the project. A deposit of DKK 1,000 (135 euro) was paid for the bicycle. It was up to the participant him or herself to purchase it from a preferred bicycle shop for up to DKK 4,000 (540 euro). During the project the University of Aalborg carried out a lot of research on the participants. Questionnaires, travel diaries and in-depth interviews were used as main sources of information. The active part of the project, where the participants were expected to not use the car, lasted from 1st May 1995 to 30th April 1996. A newsletter, several questionnaires and information meetings reminded the participants of their promise during the period. 
Finance, Resources and Counterparts

Since the project idea was entirely new and not yet tried elsewhere, the project created a lot of public attention and debate. The financing of the project was rather easy to arrange due to the existence of funds promoting environmentally sensitive traffic planning and research into transport issues.

The project was approved by Aarhus City Council. A steering committee was set up with representatives from the Transport Council (finance), The Environmental Protection Agency (finance), Bicycle Shopkeepers' Association, Danish Cyclist Federation (bicycle promotion), the University of Aalborg (research), Copenhagen Business School (research), CAT productions (marketing), Aarhus Health Council (health promotion), Aarhus Police (safety), Aarhus Transport Authority (buses) and Aarhus Municipality. A secretariat manned with two employees from the City of Aarhus was set up to take care of the organisation of greater events and the day-to-day business, including the contact with the project participants. Companies as such did not play an active role in the project. (table 6)

Table 6. The financial partners in Bike Busters projects

\begin{tabular}{|l|r|r|}
\hline Budget & Who? & How much in euros? \\
\hline Research part & TC & 131000 \\
\hline $3 / 4$ of the bus tickets & AAM & 60000 \\
\hline $1 / 4$ of the bus tickets & EPA & 20000 \\
\hline Bicycles & EPA & 94000 \\
\hline Marketing etc. & EPA & 10000 \\
\hline Marketing etc. & AAM & 7000 \\
\hline Travels etc. & EPA & 3000 \\
\hline Employees & AAM & 60000 \\
\hline Total & & 385000 \\
\hline
\end{tabular}

AAM: Aarhus Municipality

EPA: Danish Environmental Protection Agency, Transport and Environment fund

TC: Transport Council TransForsx 94 research fund

Actions

The project dealt entirely with influencing users by giving them information, care, bicycles and bicycle accessories and a rather close follow up on their activities. The actions planned were all implemented. Infrastructural improvements were not part of the project. Information was a significant part, in the recruitment phase as well as in the actual running phase. There were no genuine fiscal inducements. The project, however, involved a significant economic incentive in getting a free bicycle, rainwear etc. and free bus tickets for a year. 
A massive marketing campaign introduced the project, and a huge number of applicants were found. A majority of the participants were men, and all of them except for a few students were employed. Wish to improve health was a major factor for taking part.

The project was of the no-stick-and-only-carrot-type. The participants, though, had to sign a contract that could be considered as a 'stick-issue'. The participating BikeBus'ters should fill out 4 travel diaries (one before, two during and one after the project), each covering a week (MondayFriday). The diaries were designed to achieve results comparable with the national Danish transport surveys.

Questionnaires and in-depth interviews were also made and a recruitment flyer was produced. Besides the flyer 6 issues of a participants' newsletter were produced, which can all be considered as campaign material.

\section{Measuring the Effects}

A comprehensive research programme dealing with in-depth interviews, several questionnaires and travel diaries and health checks was from the start planned to be part of the project. Thus, it was possible to get deep insight into opinions, intensions, actual behaviour and the impact on participants' health during the project.

The project had a marked effect on the participants' transport behaviour, and several of them continued to use the bicycle after the end of the campaign, especially for the trip to and from work.

The share of car trips of the participants has changed from $77 \%$ to $46 \%$ (before the project compared to afterward), while bicycle trips have increased from $8 \%$ to $39 \%$. A partial shift back to more car oriented habits is however to be expected, unless an impulse in the other direction is repeated.

It should be noted that modal share is one thing, transport work (measured as person kilometres) another. The trips switched to cycling are the shorter ones. The BikeBus'ter population did - also during the project use the car more than the bus or bicycle, as far as the number of kilometres travelled is concerned.

\section{Motivation Factors and Opinions}

Before the project start participants were asked about their reasons to join by assessing to what degree they were in agreement with a number of statements. Health and the attraction of getting a free bicycle and free bus transport received the highest scores, ranking them as more important than caring for the environment and general cost savings in transport. (table 7) 
Table 7. Motivation factors of Bike Busters.

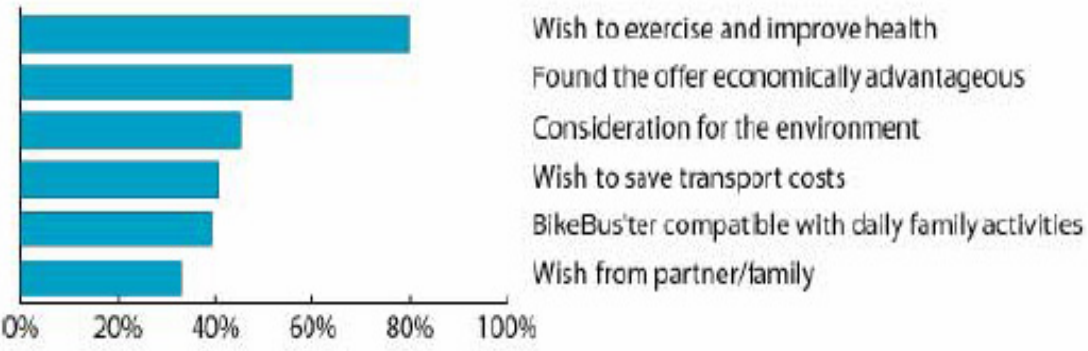

After the end of the project those who continued biking were in the same way asked to evaluate a number of statements. Again, health had the highest priority, and cost savings were felt to be the next most important.

Similarly, those who had given up their life as a BikeBus'ter were asked to evaluate a number of statements about why they did not wish to continue cycling. Compatibility with the job and weather received the highest scores.

In all cases family pressure was deemed to have just a small, if any, impact on the participants' choice. Care for the environment seems moreover not to have been an important factor.

\section{Participants and Their Behaviour}

17 did formally quit the project during its running year, typically due to change of place of work or place of residence.

There was a majority of men $-62 \%$ - among the BikeBus'ters. The great majority $-91 \%$ - lived in households with at least 2 adults. (table $8)$.

Table 8. The demographic issues of people taking part in Bike Busters.

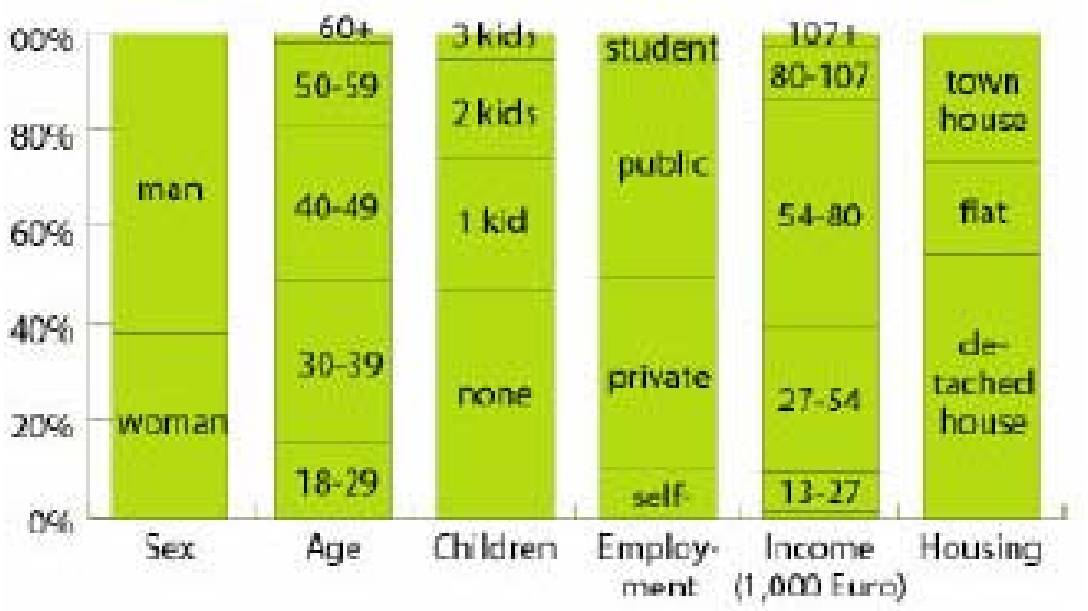

$41 \%$ of the BikeBus'ters did not initially have a bicycle. None of them had a monthly card for public transport, and a majority did not even have a discount ticket available. (table 9) 
Table 9. Availability of transport means of people in Bike Busters.

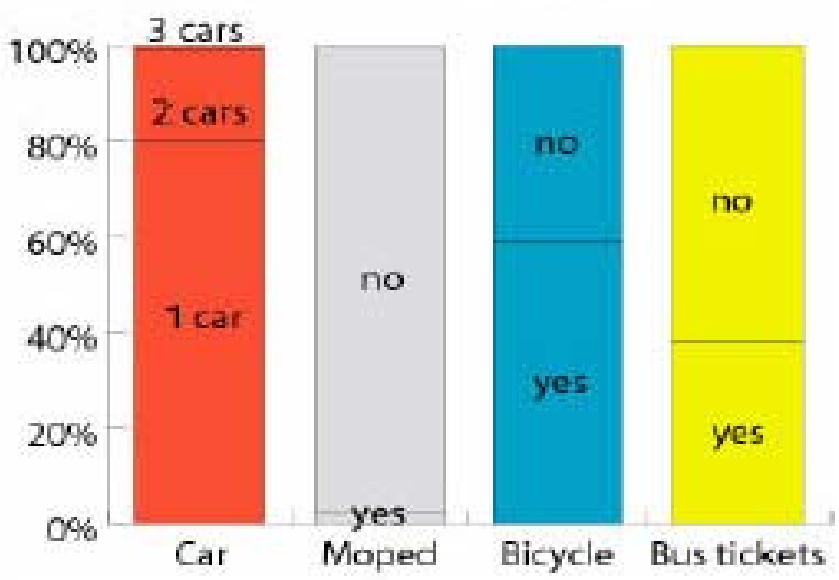

In average the BikeBus'ters lived at a distance of $6 \mathrm{~km}$ from their job. The actual travel time by bicycle turned out to be less than what was expected by the BikeBus'ters before their start as daily bicycle users. A significant change of the BikeBus'ters transport behaviour was found. The BikeBus'ters keep using the bicycle more after the end of the project than before they became BikeBus'ters. (table 10)

Table 10. Transport modes of Bike Busters before and after survey.

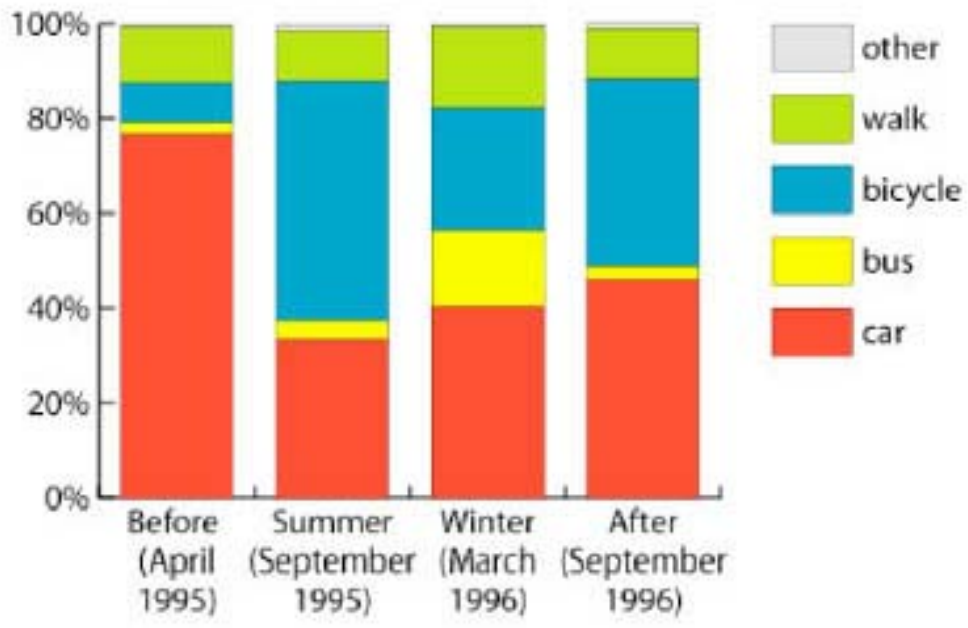

Measured in kilometres, the BikeBus'ters biked on average $30 \mathrm{~km}$ per week. Car use was considerable greater, $271 \mathrm{~km}$ per week. The bus was mainly used during the winter, which turned out to snowy one, which is not usual for Danish winters. The number of kilometres travelled and the number of bus trips were measured on a weekly basis.

There is a tendency towards a general decrease of the mobility measured as number of trips per weekday for the BikeBus'ters. Part of the reason for the decrease can however be increasing laziness in the filling-out of the travel diaries, so the tendency might be smaller than what is seen in the graph below. 
The BikeBus'ters were asked to make an account of their transport costs. The average savings were 42 euro/ month. The most extreme behavioural changes were found in the low income groups. Here, on the other hand, a bigger switch back to the car was experienced after the project period, as the economic incentive ceased.

\section{Accidents}

There were 7 accidents with BikeBus'ters in the project period. Four of them were sole accidents, 3 were collisions with motor vehicles. The two most serious personal injuries were a broken leg and a head-impact resulting in permanent, partial deafness. The number of accidents is unexpectedly high taking into account the number of kilometres travelled, and might be due to the sudden introduction of non-trained cyclists to a new traffic situation. Generally, however, the BikeBusters feel safe in traffic.

\section{Health Effects}

Health checks were carried out before, during and at the end of the project. Measurable effects on the participants' health were found. The share of participants with a poor physical condition fell from $35 \%$ to $18 \%$ during the first half year. It increased somewhat again during the winter, but never reached the initial value. Positive effects, though to a smaller extent, were also found for blood pressure and cholesterol. Weight was about unchanged, though with some tendency towards fewer people with a very high or very low weight. Remarkably, two out of three participants generally felt their health and wellbeing to have been improved during the project. 


PIKEBUS'TERS
Project Summary Card
To the right: Examples of
information material
Project duration/period, financiers and partners, budget
Duration: $1995-1996+$ planning before the project and research after
Financiers and partners: City of Arhus; Danish Environmental Protection Agency
(Transport and Environment Fund); The Transport Council (TransForsk 94 research
fund)
Budget in EUR: 385,000
Project aims
To investigate to what extent habitual car drivers could use bicycle and bus for their
daily transport.
Actions taken
Setting up a BikeBus'ter coordination office; broad marketing of the offer of a free bicy-
cle and free bus tickets; selecting 175 of the applicants to become BikeBus'ters; sup-
porting the BikeBus'ters, issuing newsletters and organising events; carrying out health
checks.
Evaluation methods
Travel diaries; questionnaires; in-depth interviews; investigation of bus tickets; tracking
of bicycle computers and car odometers.
Results
Substantial change in transport behaviour towards more bicycle use and less car driv-
ing, especially for the journey to work. Bus mainly used during tough winter conditions.
Modal split for bicycle changed from $8 \%$ to $50 \%$ and for car from $77 \%$ to $33 \%$. Even
after the project, bicycle use is still $39 \%$ and car use $46 \%$.
Learnings/experiences
Interest in personal health was a main factor behind the change. Significant changes in
transport behaviour can be achieved by positive measures combined with support and
surveillance.

\section{HUR Pendlerkontor}

Starting Phase

The Greater Copenhagen Authority (HUR - Hovedstadens Udviklingsråd or GCA - Greater Copenhagen Authority) set up the HUR Pendlerkontor (GCA Commuter Office) in the autumn 2002. HUR Pendlerkontor's aim is to develop transport plans for businesses and institutions in the capital area. In the short term, HUR Pendlerkontor aims to investigate to what extent businesses and institutions are interested in developing such transport plans and to evaluate the effects on the transport behaviour of their employees. Underlying this is the objective to identify which barriers should be overcome to achieve the desired behavioural changes. The long-term goal is to reduce congestion, increase sustainability of the transport system and improve employee health. 
The starting phase of HUR Pendlerkontor was the political backing given by HUR Council in April 2002. The main background to the decision was a wish to fight congestion without having negative impacts ("sticks") on daily car users. Environmental considerations were not a key issue. Before the decision a screening of about 80 possible businesses to take part had been carried out. (Haas 2003)

The starting phase of HUR Pendlerkontor was expected to last for 2 years with a staffing of 3-4 full-time persons. The office became permanent in 2004 with a staff of two persons. The plan was to prepare 6-8 transport plans in the first year and to evaluate their effects. (Haas 2003)

Finance, Resources and Counterparts

The budget for the starting phase was 1.55 million DKK (208,000 euro) per year for staff, consultants and miscellaneous expenditures. For the latter 0.8 million DKK (106,000 euro) per year was set aside, which was more than sufficient to pay consultants, computer programmes, printing, computers and office furniture. On top of this people already employed at HUR were expected to spend part of their time on the project. The whole budget was financed by HUR.

A steering group with representation from several HUR departments, among them the administration, met once a month to discuss the project progress. An employee from the Transport Planning Department was responsible for the day-to-day management of HUR Pendlerkontor. The HUR Council was to decide on a mid-term evaluation and a possible prolongation of the project.

Informal links were established to counties and municipalities in the area, as well as other partners dealing with Mobility Management issues. Companies were counterparts in the actual transport plans carried out, but not in the work as such. The board of a major industrialists' association was informed about the activities at one of its meetings.

In practice it has not shown possible to find businesses with a wish to coordinate environmental planning and management with transport management. The journey between home and place of work is still primarily seen as a private issue, and one for the road and public transport authorities to solve.

The staff and consultants involved have an academic background in traffic planning, environmental planning, organisational development, political sciences and transport behavioural campaigns. The link to the businesses usually is a person from the Human Resources Department.

The staff at HUR Pendlerkontor often involves municipalities in questions dealing with infrastructure, as well as the bus planning division of HUR as far as the bus services are concerned. This enables quick replies to specific questions and to some extent the possibility of making changes. Infrastructural changes are, however, usually difficult to bring 
about over the short timespan involved in preparing a transport plan. (Haas 2003)

Actions

In the transport plan work, a number of activities have been planned:

- Surveys of employees about mode choice including problems/wishes as well as readiness to change

- General information about public transport and cycling to the company in question

- Specific information about public transport and cycling to individual employees

- Information to employees about "matches" with other employees for carpooling purposes

- Discussions with management about flexible hours of work, working from home and videoconferences.

This has all been done in practice. Transport's impact on managements' view on flexible hours and working from home is, however, quite limited. Some have it, some not, and transport is just a minor consideration in this connection.

To prepare transport plans, it is first necessary to find businesses that are interested. Several activities were carried out with this purpose. It was found, that businesses in the process of relocation are much more interested in discussing transport than the average business. This is true for the employees as well as for the management, as employees' problems quickly become an issue relevant for the management.

No stick is available in connection with transport plans, and the main carrot is information. It has however shown to be very useful to introduce visible matters like commuter bikes (i.e. bikes to be used between the place of work and a train station or major bus stop). Also improved bus services are possible e.g. a bus stop was relocated from one street to another in connection with one of the transport plans.

Tools and Material

Web based electronic questionnaires have been used very often. HUR Pendlerkontor has bought a special programme (Quaestio) for this purpose. Another tool purchased is a programme (Pendlercheck) that identifies matches for car pooling, i.e. people with home addresses nearby. The input to the programme is the employees' addresses, which the programme converts to GIS coordinates for further analysis. The programme is also able to identify which addresses will be close to the preferred route of other employees living further away. 
Company-specific information about public transport and cycling has been provided to the businesses in question in the form of websites accessible from the intranet.

A leaflet for the recruitment of businesses has been produced. Often articles in employees' newsletters have been written. The need for an electronic bicycle route planner for the Greater Copenhagen Area has been identified.

Philosophy and Method of Work

The philosophy behind transport plans is to investigate the employees' current transport behaviour and their interest in alternatives. Based on this, changes and actions are brought about, which will make the employees change their transport choices. Common measures in a transport plan are:

- Car pooling (more than one person per car)

- More use of public transport

- More use of bicycles

- Combinations of various transport means, e.g. car/bicycle and public transport, also by the use of park \& ride sites.

Flexible hours of work, videoconferences and working from home can also be important elements in a transport plan.

If possible, HUR Pendlerkontor starts with a focus interview with key employees. After this a questionnaire is distributed to all employees. The responses enable an overall analysis of the transport behaviour and preferences among the employees. Based on this HUR Pendlerkontor proposes alternative solutions, initiatives and policies, that can motivate the employees to adopt a more sustainable transport behaviour. Such proposals can be the purchase of commuter bikes. It can also be the establishment of a club for carpooling, where interested employees can find partners. Often improved information about use of bicycles, public transport and park \& ride facilities will be part of the plan. The proposals are discussed with management, and the results are the basis for designing the transport plan. Evaluation of the effects is carried out about half a year after the proposals have been realised.

Recruitment and Information

Businesses and institutions interested in elaborating transport plans have been identified in different ways: by direct approach, by a leaflet sent to major businesses in the Greater Copenhagen Area, and by articles in the press. (picture 4) 
Picture 4. A leaflet was distributed in order to ease contact and provide general information.

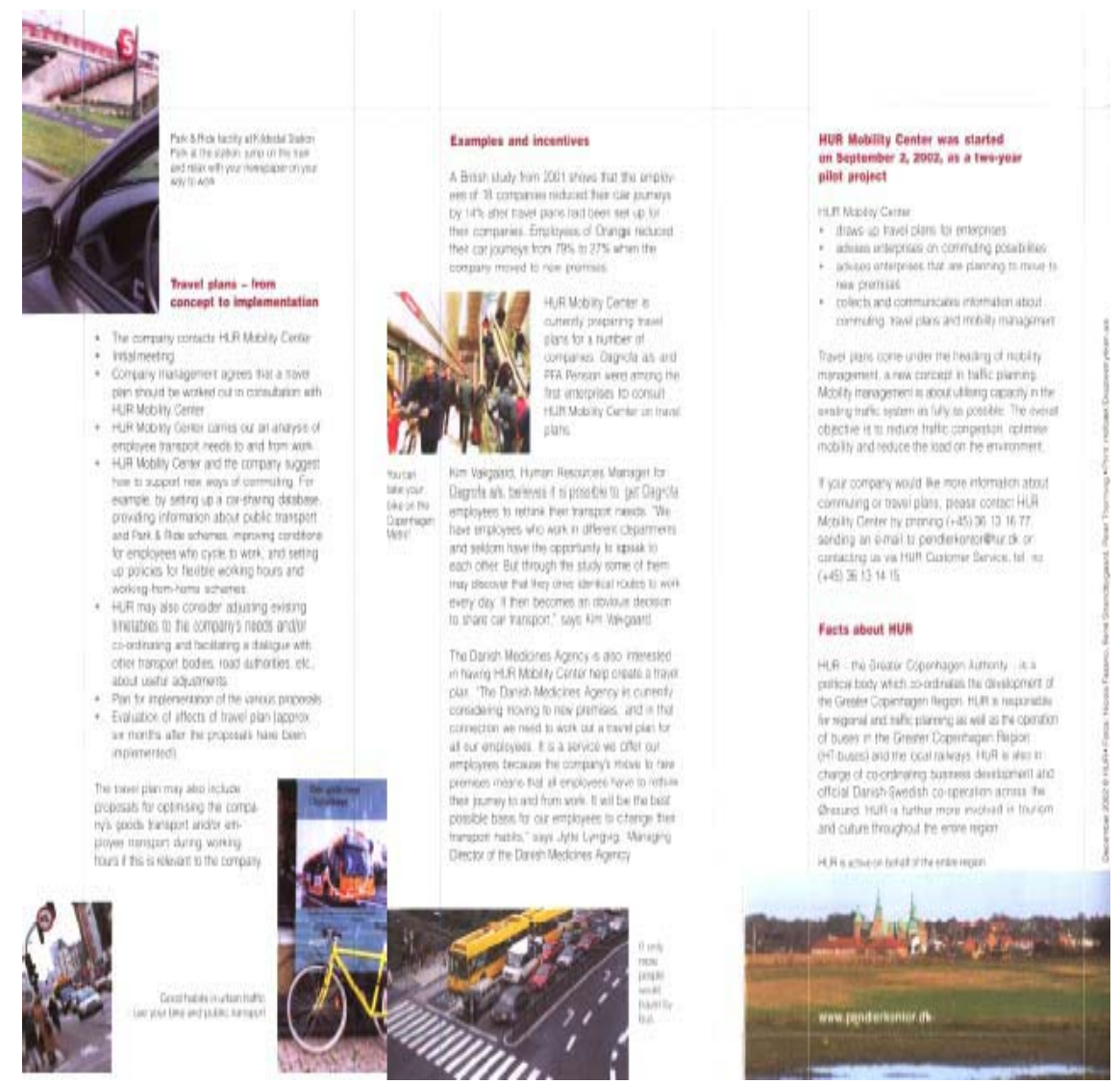

Moreover, to improve the general information level about HUR Pendlerkontor, transport plans and Mobility Management, a newsletter has been sent out regularly since June 2003 . The newsletter is published in hardcopy as well as electronic versions.

Website

The website is set up as part of the HUR website (picture 4), but with its own address. The website gives general information about Mobility Management and specific information about the Pendlerkontor activities. The newsletter can also be assessed via the website. The website address is www.pendlerkontor.dk.

Production

In the first one and a half years HUR Pendlerkontor has prepared transport plans for 9 private businesses and public institutions in the Greater Copenhagen Area. Besides this, other minor services have been provided for a number of other businesses. HUR Pendlerkontor, moreover, has been in contact with several businesses 
The transport plan work has involved the following activities:

- For each of the businesses involved thorough information about relevant public transport services has been provided on an internal webpage.

- Articles have been written for employee newsletters.

- Individual travel information for public transport has been provided for 421 persons.

- 142 cycle route proposals have been developed and communicated to the same number of persons.

- Matches for car pooling has been made for a total of 687 persons.

- 20 commuter bikes have been loaned to two businesses, based on two different concepts.

Several meetings has been organised with staff of the businesses taking part. (HUR Pendlerkontor 2004)

Result

Except for the number of transport plans to be prepared, no target results were initially set up. Nine transport plans were drawn up the first year. A cautious estimate is that the transport plans have resulted in 25 cars less on the arterial roads of Copenhagen, and a reduction in car use amounting to $7,800 \mathrm{~km}$ per week. This means annual savings of 60 tonnes of $\mathrm{CO}_{2}$ emission.

Visible features such as the provision of commuter bikes and relocation of bus stops have shown to be very successful. Information services are also welcomed, if it is clear beforehand what the content of the service is.

An evaluation of 6 out of the 9 transport plans has been carried out. Among the lessons learned are (table 11):

- Especially businesses in the process of relocation are motivated to participate in Mobility Management activities.

- Between one third and a half of the daily car users at the businesses involved are ready to reconsider their transport behaviour, provided attractive alternatives are presented, and other complimentary measures are carried out.

- There is a good potential in physical mobility services (e.g. commuter bikes).

- Daily car users can be motivated to reduce their car use, but not to completely give up the car for the journey between home and work.

- The presentation of Mobility Management services needs to be very precise as far as what the service offered actually comprises. 
- A flexible approach dependent on the business in question is necessary - one fixed scheme for the development of a transport plan will not work.

Table 11. The knowledge about and satisfaction with the offered mobility services of the 6 businesses in the evaluation of HUR Pendlerkontor.

\begin{tabular}{|c|c|c|c|c|c|c|}
\hline & 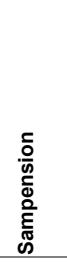 & 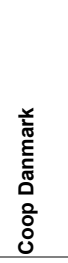 & 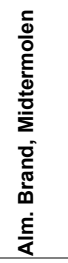 & 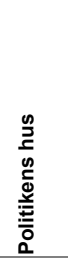 & 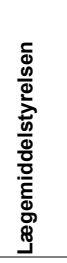 & 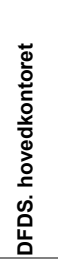 \\
\hline $\begin{array}{l}\text { Knowledge about the offered services } \\
\text { and initiatives (the transport plan) }\end{array}$ & $95 \%$ & $62 \%$ & $61 \%$ & $26 \%$ & $95 \%$ & $61 \%$ \\
\hline $\begin{array}{l}\text { Number of employees who have accep- } \\
\text { ted at least one offer }\end{array}$ & $56 \%$ & $20 \%$ & $20 \%$ & $2 \%$ & $46 \%$ & $29 \%$ \\
\hline $\begin{array}{l}\text { Satisfaction with individual information } \\
\text { on public transport }\end{array}$ & 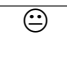 & : & :) & - & $:$ & ;) \\
\hline Satisfaction with bicycle route proposals & ;) & - & : & - & : & (;) \\
\hline $\begin{array}{l}\text { Satisfaction with matches for shared } \\
\text { ridership }\end{array}$ & 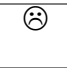 & 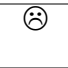 & $:$ & $:$ & : & : \\
\hline Satisfaction with commuter bikes & (;) & - & - & - & (;) & - \\
\hline
\end{tabular}

From this it is concluded, that

- communication about public transport information shall be very precise on what is actually offered

- bicycle route proposals are generally a good idea, and an electronic cycle route planner would be beneficial

- attempts to match employees for is only interesting if several thousand employees are involved at the same time

- commuter bikes is a successful and very visible measure. (HUR Pendlerkontor 2004) 
Picture 5. Information in English of HUR Pendlerkontor.

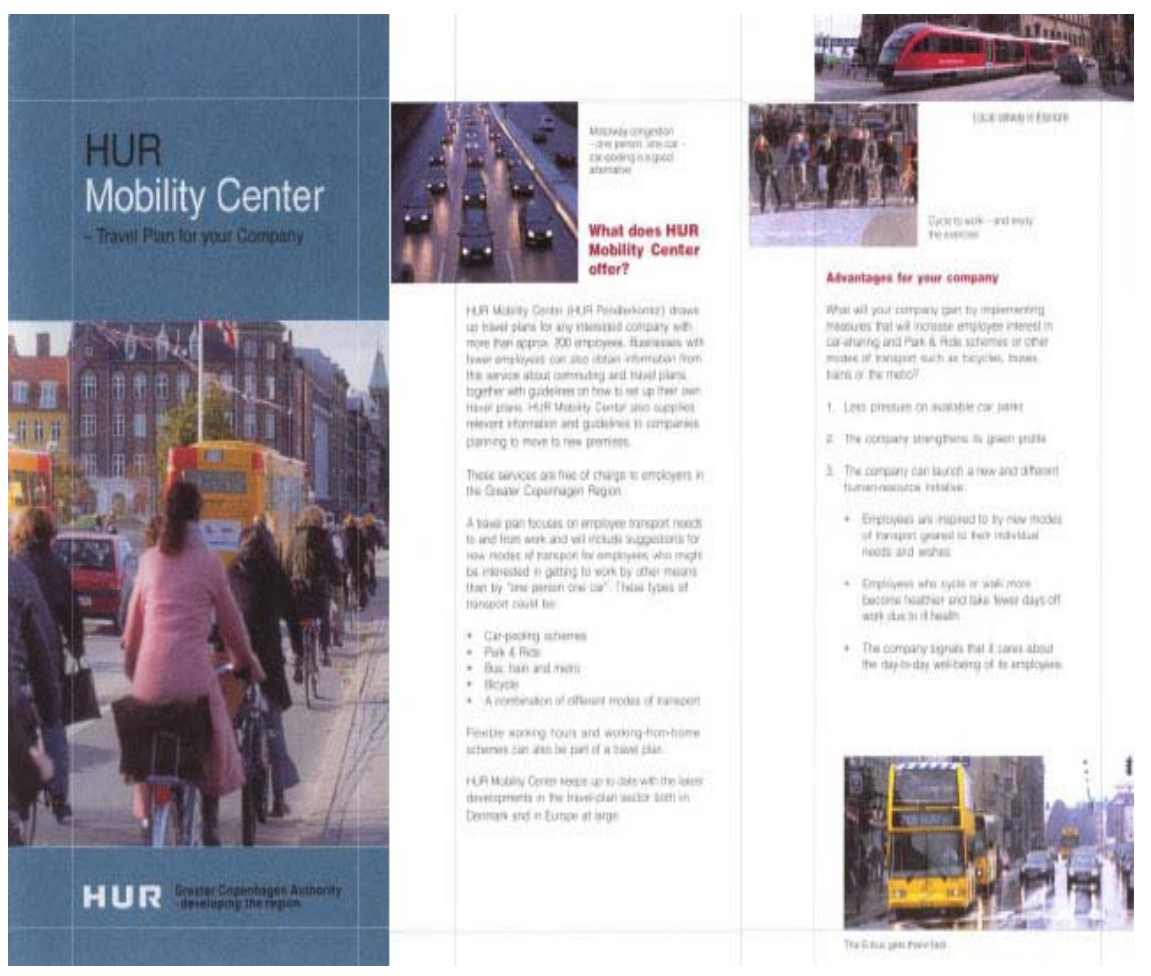




HUR Pendelkontor
Project Summary Card
To the right: Examples of
information material
Project duration/period, financiers and partners, budget
Duration: $2002-2004$ with activities continued afterward
Financiers and partners: Greater Copenhagen Authority (HUR, Hovedstadens Ud-
viklingsrád)
Budget: 200,000 euro per year in the two-year experimental phase
Project aims
To investigate: to what extent it is possible to develop transport plans for businesses
and institutions; and what their influence on the travel behaviour of employees will be.
Actions taken
Contacting places of work; setting up an office, marketing, making transport plans, pro-
viding several mobility services, evaluating transport plans.
Evaluation methods
Questionnaires to employees.
Results
22 car users (i.e. $6 \%$ of the respondents formerly using a car) ended up using their car
on average 3 days less a week
Learnings/experiences
IThe more concrete and visible offers the better ("commuter bikes" - bikes available
between work and a nearby station - are a good example). Businesses in the process
of relocating are the most interested. Communication about offered mobility services
should be very precise.

\subsection{Norway}

\section{SMART Project in Oslo}

\section{References:}

SMART Information: Interviews of Olav Kasin and Ragnhild Grindland Company information and travel surveys: Interviews of people in charge in different companies.

Background, aims and context

The SMART project in Oslo is a cooperation project between the National Cyclist Federation (SLF), the collective car organisation Bilkollektivet, the main public transport company in Oslo, Oslo Sporveier, and the National Automobile Federation (NAF). Plans are that the project in its current form will be finalised by the end of 2004, but it is hoped that the 
most successful actions will be followed up and developed further by the companies involved - in a more integrated way as part of their daily business operations.

The vision of the SMART project in Groruddalen, Oslo has been "Improved access to, and information about, the best possible forms of transportation for employees in the area, with regard to both economy, environment and health". The main aim of the efforts launched has been to increase the use of public and non-motorised transport. Additional goals were to improve the utilisation of private car transportation in order to improve the environment and the images of the businesses in the area. A mobility advisor has been hired to work part-time (50\%) over a prolonged period of time, instead of full-time during a shorter period. A website has also been established as part of the project.

The main work in the project has been to offer a limited number of companies/organisations consulting advice on how to improve employee travel behaviour, so that positive effects related to economy, environment and health could be realised. Initially, the project involved three organisations, but as the work progressed, one of the businesses withdrew, and two new ones were included. This means that four businesses are currently involved; namely, Siemens, the local municipal administration of Bjerke, Tollpost Globe, and Linjegods. In other words, a big electronics company, a municipal administration office (including the division of social welfare's home care services for the elderly), and two transportation companies.

The work includes both actions related to physical improvements (including better access to public transport and infrastructure for nonmotorised transport) as well as information and motivation efforts. The focus is on offering the selected companies business specific counselling in Mobility Management. The SMART project is part of the larger programme "Environmental Travels in Groruddalen", which also includes a number of other actions, actors and forms of collaboration. Its overall aim is to make transportation in the valley more sustainable in a far-reaching and long-term sense.

\section{Finance, Resources and Counterparts}

The total budget for the project has been 1 million NOK (125,000 euro). More than $50 \%$ of the total costs are related to the mobility advisor, who was working directly with the companies involved. Providing ideas, guidance and support on implementing different actions have been the most important tasks.

The project has had 4 financial contributors. The municipality of Oslo (the Department of Transportation) has provided close to half of the needed resources (45\%), while the Ministry of Environment and the Road Authorities have contributed 25-30\% each. 
A steering group comprising the municipality, the ministry of environment, and the regional road authorities has headed the project. The practical work has been carried out by a working group comprising representatives from the National Cyclist Federation (SLF), the collective car organization Bilkollektivet, the main public transport company in Oslo, Oslo Sporveier, and the National Automobile Federation (NAF). A mobility manager was hired to be in charge of the work.

In addition to the organisations responsible for heading and administering the practical work in the project, the following parties have been involved; 5 businesses (private and public), the national railway company, some other transportation operators, property owners and local business organizations. The main contact persons in the businesses have been managers of health, environment and security, quality managers, or leaders of LA 21-work (Local Agenda 21 efforts of creating more sustainable local communities).

The most active parties besides the businesses themselves seemed to be the municipality and the national road authorities, both working on programmes related to Mobility Management. Continuous efforts from the other actors have been hard to secure.

\section{Siemens}

In the Siemens case, emphasis has been placed on improving the infrastructure for non-motorised transport. Reduced speed, better signposting and physical improvements in the area of accessing the company's facilities are among the most important efforts, besides providing better facilities for showering and changing as well as storing and drying clothes.

A discussion forum for the users of the area (not only Siemens) was established, where employees and others could point at problems and challenges and come up with ideas on how to improve matters. Railroad authorities, local transportation operators and the municipality were also represented in this forum. The core idea with this arrangement was to create a tighter link between users of the area, the management of the businesses, public authorities and transportation operators.

An attempt has been made to get public transport fully or partly subsidised by the company, but this effort has now been altered due to external problems on the public transport system (on the specific line serving company's premises). This effort, however, will be followed up by trying to find another suitable company situated along another public transport route.

The most important experience of the project, expressed by the manager of health, environment and safety, who was in charge of the project, was the illumination of how everything previously had been facilitated for car transport as if it was the one and only mode of transport. This fact 
was clearly revealed, and the need for change consequently became more transparent and understandable.

Quite a bit of "internal marketing" has been accomplished, using the organisation's intranet and launching a variety of pricing schemes, to pursuade more people to choose physically active transport modes when possible. Overall, the experiences in the Siemens case has been very good, choosing to go for a limited number of actions and being a bit patient with following up on these. Since the company is so large and has operations at 14 different locations countrywide, it also has a great potential for further actions and improvements.

The project leader points to the need for changes in the tax system, as the different transport modes should be treated equally.

The Municipal Administration of Bjerke

In the local municipal administration of Bjerke, two divisions have been involved; the administration unit (about 50 employees) and the division for social welfare's home care services for the elderly (about $200 \mathrm{em}-$ ployees). The project's vision was from the very beginning quite clear, to place environmental transport on the agenda. Environmental questions related to transport have been introduced and focused in a number of ways, and even though one has not yet managed to quantify any effects in practice, there are clear signs of progress.

In the administration, focus has been placed on information about various travel possibilities. The main information unit for public transportation in Oslo, Trafikanten, has been involved at specific information meetings for the employees, and various forms of information channels have been explored ("green lunches", posters, intranet, etc). These kinds of activities have received good response from the employees, who often did not know what options for public travel actually existed. Carefully targeted information about the public transportation system therefore proved to be efficient. A "travel guide" has been developed on the intranet, with links to other valuable websites having cycling maps, public transportation routes, etc.

In the division for social welfare's home care services for the elderly, emphasis has been placed on replacing the use of cars with bicycles to the greatest extent possible. Cycling courses have been arranged, as many of the employees had not been biking for years, and a number of bicycles for use for work purposes have been acquired. The rather compact area of this part of the city makes cycling an excellent option for short trips between the care homes. Both rain clothes and information on wardrobe facilities have been provided, as well as free maps of cycling opportunities. A main challenge has been to promote these contributions as positive extras, not as "regulative". This is because the employees are kind of fed up with all kinds of cuts due to stricter budget limits for several years already. 
An application to the municipality about offering the same economic benefits for bicycle use as for car use for on duty trips has been turned down, but Bjerke and the national bicycle association are both determined to follow up on this issue. Bjerke has recently approached the municipal department of finance with a clear request to solve the issue.

The project leader notes if the umbrella project were more action oriented then it would have been easier to "get things going". Things seem to proceed quite slowly, and this contributes to "setting the atmosphere" also for the company-specific efforts (attention and motivation among employees and all the different parties involved).

\section{Linjegods and Tollpost Globe}

The businesses of Linjegods (350 employees) and Tollpost Globe (400 employees) were included in the project at a rather late stage, about February 2004, when it was recognised that things moved relatively slowly in the other businesses, and Oslo Vei decided to withdraw. Both these businesses are located in an area where there is a lot of activity (Alnabru). They were both recruited through contact with the National Confederation of Business and Industry.

A crucial challenge is mapping the employees' housing locations, since better public transportation requires specific proposals to the public transportation operators. The use of GIS is therefore now being explored, and Oslo Sporveier seems to be open to suggestions about improvements in their routes and frequencies. The municipality has financed part of these efforts. SMART Oslo wants to further develop further these "mapping exercises" and the National Confederation of Business and Industry is striving to entice more businesses to the area.

So far, the efforts in Tollpost Globe primarily have included more busses and shelters at the main bus stops, as well as improving the logistics within the business area, which is rather large. Some improvements in public transportation routes have also been achieved. A somewhat more comprehensive action plan also will be prepared in the near future. Improved use of Intranet, as well as better connections to "Haiketorget", a national website for car-pooling, will be emphasised in the time to come.

The mobility manager is very clear about the need to work in parallel on the practical and strategic levels, as well as being tactical about timing in all efforts. Establishing a tight link between strategy and actions is viewed to be an important challenge. This linkage must also be understood and supported by all involved parties. The importance of creating visible results and manifestations at an early stage also seems to be crucial.

In Linjegods, a rather comprehensive travel survey was carried out in May 2004. It is a good base for developing an action plan. A number of suggestions for improving the situation for non-motorised and public 
transport were identified. In addition it offers the possibility to map employees residences, transportation services and options. The share of employees using public transport is already quite high, but among the commuters using their private cars, $50 \%$ do not know what public transportation alternatives exist. The main information unit of the public transportation system in Oslo, Trafikanten, has therefore been involved in improving the employees' knowledge. Special efforts are also placed on encouraging people to carpool, as many employees live quite far away from work. Information about Haiketorget (the largest website for carpooling in Norway) is provided, and the potential of using the company's intranet is being explored and developed in relation to this site. Slight improvements in public transportation routes have been achieved, and shelters at bus stops have been established.

\section{Oslo Vei}

Oslo Vei has about 160 employees and agreed to participate in the project in the beginning of 2003. However, the management decided to withdraw from the project relatively soon thereafter; the main reason being that Mobility Management was not part of the environmental certification system "Miljøfyrtårn". Motivated primarily by this, the company did not want to spend time and resources on a SMART project. Another possible reason for withdrawal might be a rather low quality travel survey that was carried out. The lesson learned is to anchor the project securely at top levels from the very beginning, with sufficient clarifications of aims and assumptions, and to carry out all activities effectively.

\section{Tools and Material}

Travel surveys were carried out in all of the participating companies, with varying response rates. Bjerke only achieved $37 \%$, while Siemens reached $67,5 \%$, Oslo Vei $42 \%$, Linjegods $67 \%$ and Tollpost Globe $74 \%$. The value of these surveys has varied, with the companies carrying out the surveys the latest (after improvements) having the best use of them. Ideas about what can be done to improve the situation for public and nonmotorised transport were identified in all the surveys, but knowledge about the employees' travel behaviour was only generated in a couple of cases.

The National Road Authorities are working on improvements for standardizing the travel survey methods, trying to find the right balance between being short and easy, and still detailed enough to give the necessary information. Relatively short questionnaires sent by e-mail seem to be the best method, but it is a challenge to develop standard surveys that fit all cases.

About $10 \%$ of the project resources in the SMART project has been used for information material of different kinds. Initially, one aimed at developing a brochure for potential businesses and organisations to get 
them involved in the project, but later the focus was on general information about the project. The efforts were coordinated with the umbrella project "Environmental Travels in Groruddalen". Two brochures (picture 6) have been developed; one with general information about the project, and one targeted towards potential cyclists. The latter one was developed in cooperation with the umbrella project.

Intranet has been utilised actively by both Siemens and Bjerke, and their efforts seem to be efficient. Both these companies want to further develop their use of intranet. Company-specific information, motivational campaigns, and links to other important sources of information (public transport routes, bicycle maps, etc) have been well received among the employees, and more and more employees are using the net actively.

The possibilities of connecting the use of intranet with Internet have note yet been explored much, but there seems to be a potential related to "Haiketorget", a national hitchiking/carpooling site for getting in touch with people driving the same route during the same time.

Picture6. Examples of marketing material in the SMART project.

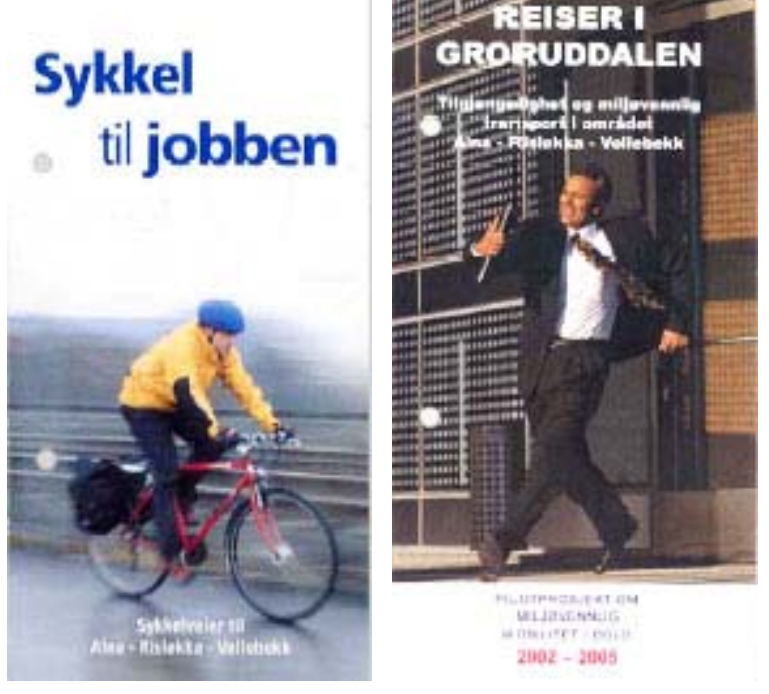

Measuring Effects

None of the businesses involved have carried out surveys after the implementation of the actions yet, so it is therefore not possible to describe effects and results quantitatively. Whether such "after surveys" will be accomplished depends on the projects future, which will be decided upon in the beginning of 2005. The survey methods have been improved during the project, however, and it is hoped that some of the businesses will carry out new travel surveys in 2005, 2006 or 2007. It would then be possible to detect changes in modal split and effects related to economy, environment and health, which would be of crucial importance with re- 
gard to motivating both private companies and public authorities to continue with their Mobility Management efforts.

Important Experiences

It is not known whether the main aims of the efforts in SMART Oslo, of increasing the use of public and non-motorised transport, and improving the utilisation of private car transportation, have been achieved, but there is reason to believe a positive development has begun. Making visible the positive effects of the project work is considered crucial, but this is a rather ambitious and demanding goal, as the necessary tools for doing this need to be developed. Individual businesses/organizations need to be provided the right tools for accomplishing such tasks. The companies also need to get aware of their responsibilities, as well as competitive possibilities, of being more environmentally sustainable, including the travel behaviour of their employees. This might be also be an important factor behind employees health. 


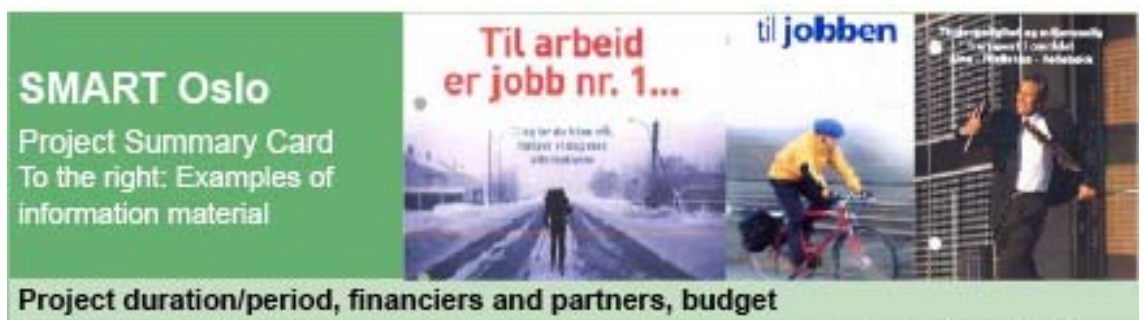

Project duration/period, financiers and partners, budget

The main project work has been carried out over two years, ending in the fall of 2004 . The project, itself, was originally initiated in 2001. It is not yet clear whether it will continue in its current form or through some other kind of organisation. SMART Osio is a cooperation project between the National Cyclist Federation (SLF), the collective car organization Bilkollektivet, the main public transport company in Oslo, Oslo Sporveier, and the National Automobile Federation (NAF). It is financed by the Municipality of Oslo, the Ministry of Environment, and the National/Regional Road Authorities. The total budget for the project has been about 125000 euro.

\section{Project aims}

The vision has been "improved access to, and information about, the best possible forms of transportation for employees in the area, with regard to economy, environment and health ${ }^{*}$. The main aim of the efforts launched has been to increase the use of public and non-motorised transport. Additional objectives are to improve the utilisation of private car transportation in order to improve the environment and the images of the businesses in the area.

\section{Actions taken}

The main work in the project has been to offer a limited number of companies/organisations consulting advice on how to improve employee travel behaviour, so that positive effects related to economy, environment and health could be realized. The work includes both actions related to smaller physical improvements, better access to public transport and infrastructure for non-motorized transport as well as to information and motivation efforts.

\section{Evaluation methods}

Travel surveys have been carried out in all the participating businesses, both as part of finding the best actions to be taken in the given situation, and in order to detect changes in travel behaviour and modal split at a later point of time.

\section{Results}

None of the businesses involved have carried out after surveys yet, so it is not possible to describe effects and results quantitatively. However, there is reason to believe a positive development has begun even though the results so far must be characterised as rather marginal.

\section{Learnings/experiences}

There are no one "best way or solution", but a range of possibilities different companies need to explore themselves. Individual businesses/organizations need to be provided helpful tools. They also need to be made aware of their responsibilities, as well as competitive possibilities, of being more environmentally sustainable.

\subsection{Finland}

\section{Alf - a local transport forum in Jyväskylä}

The mid-sized city of Jyväskylä in Central Finland has been working on Mobility Management issues in 2003-2004. Local transport forums generated ideas regarding sustainable travel to schools and workplaces. Travel surveys have been carried out at workplaces and schools. Important parts of the work have been marketing through events etc and creating local 
action plans. Three work places were involved in the project: the City of Jyväskylä, social and health services (40 employees), health authorities (5 000 employees) and the Road Administration (40 employees). Small actions were carried out, e.g.

- More sheltered bicycle stands

- Action day (cycling, health tests etc.)

- Better social premises at new office building

The budget for the projects was 25,000 euros (one year) and it was funded via the National Climate Change Communication Programme. The project ended in 2004 and possible further plans are in the planning phase. The project did not produce any brochure but some information can be found from the Internet. Since after surveys have not been carried it is difficult to estimate the real effects.

Pekka Niska - "In praise of fitness" program

One company example which was used in marketing the concept in Jyväskylä was Pekka Niska. This company is one of Finland's largest lifting equipment companies. Their "staying fit for work" program for staff promotes exercise during commuting. In line with the managing director's own enthusiasm for fitness (Pekka's goal is the $100 \mathrm{~km} \mathrm{run/} \mathrm{cham-}$ pionship of the veterans' marathon) the staff is encouraged in many ways to take care of their own fitness in order to cope better both at work and at home. The UKK Institute's walking test is carried out every six months. According to the level of fitness there is the possibility of a small financial increase in monthly earnings. Workers are also encouraged in other ways to have a healthy lifestyle. Taxable bonuses are paid at Christmas-time if the entire preceding year has passed without "vices" (table 12). (www.pekkaniska.fi/c/en/info/stamina/jsp)

Table 12. Annual company bonuses at Pekka Niska

\begin{tabular}{|l|l|}
\hline no days off work & $340 €$ \\
\hline no smoking & $170 €$ \\
\hline no alcoholic drinks & $170 €$ \\
\hline one official marathon & $170 €$ \\
\hline
\end{tabular}

Staff has the possibility to buy fitness equipment at reduced prices, to use the company's gym free of charge, to participate in an organised fitness circle and to receive personal guidance. The company also pays for participation in fitness events, exercise sessions in private gyms etc. Transport modes such as cycling and walking are thus encouraged through their connection with health issues. 
Company Mobility Management - Research and Development Project

A research and development project, "Työnantajien mahdollisuudet työmatkaliikenteen hallinnassa" was launched on company Mobility Management in 2001. Financers for the project were the Ministry of Transport and Communication, the Ministry of Environment, City of Helsinki and Helsinki Metropolitan Area Council. The budget amounted to some 20 000 euros. The project examined central policy instruments (laws, taxation etc.) that affect commuter traffic.

The pilot project was carried out in four working places in Helsinki and the neighbouring City of Vantaa. Work places selected were the Ministry of Transport and Communications, the Ministry of Environment, Sonera (a tele-operator) and the Peijas-Rekola hospital. The main aim of the project was to gather data on employee traffic patterns and possibilities to change them. The project tried to identify possible marketing issues and counterparts in the companies. A questionnaire (paper and internet versions) on commuting patterns and on attitudes to changing travel habits to more environmentally friendly modes was sent to all employees. Employers were also interviewed. Designing and implementing practical actions was not the focus of the project and there has been no follow-up. 



\section{Future Promotion of Mobility Management in the Nordic Countries}

A number of actions can be taken in order to promote Mobility Management. At the company level the actions relate just as well to policy instruments as marketing and information. Most important is to find an effective package of measures and to create positive prototypes. The administration should put more effort on marketing the issue, financing pilot projects and shouldering the responsibility for longer-term development and evaluation.

Policy instruments should give a clear message that environmentally sustainable and healthy modes are favoured. More important than numbers (taxable value, deduction limits etc.) are the principles behind policy instruments. The psychological effect can be even more powerful than the monetary benefit a person receives from a policy instrument. Most policy instruments handle only car driving (company cars, parking norms) which gives a message that other modes are not included in the systems an employer should be handling. For companies the main marketing arguments are the economic benefits of Mobility Management.

National figures concerning taxation of benefits, compensation rates, deduction limits etc. are always affected by several external factors, such as the overall income tax, fuel price etc.An absolute comparison is thus not relevant. The policy instruments available seem to be quite similar in the different countries, except for the swedish practice of taxation of car parking and environmentally friendly cars.

This chapter includes recommendations on actions that could promote Mobility Management on a Nordic level. The recommendations are formulated by the MOPPI consult group and do not represent the official opinion of the Nordic Council of Ministers.Developing policy instruments. 


\subsection{Developing Policy Instruments}

\section{A Developing EMAS and ISO Certificates to Include Transport}

Companies and other organizations are increasingly implementing and developing environmental and quality management systems. Environmental management systems help companies and other organizations to define major environmental impacts related to their activities, indicators to measure these impacts and potential actions to reduce the harmful ones. The environmental management systems require that organisations define and measure their environmental impacts. However, the systems as such do not provide tools or set criteria for the definition and measurement of impacts. The travel behaviour of the companies' staff is seldom taken into consideration in environmental systems due to the lack of awareness and knowledge of the impacts of the travel patterns. Commuter traffic is often seen as an area where the employer should not be involved. This is a fact even though commuting problems can have remarkable impacts on availability of labour and effectiveness of work.

Transport issues would be focused upon if the guidelines and lists of possible actions and indicators would be a part of the management system. Since many of the environmental and quality management systems are standardised or otherwise defined at an international level, it is important to look at the systems not only at an organisational level but also at national and international levels. Therefore it is recommended to establish contacts to some European or global organisations such as ISO, EFQM, EMAS, IQNet and European co-operation for Accreditation (EA). For example ISO has a global coverage with 200 country organisations. The role of the standardisation organisations is to provide feedback on the final results and recommendations. At the local level, the counterparts are those having the right to ratify national standards.

It should be also considered whether the promotion of Mobility Management could be closely integrated into such European and international processes as the Cardiff process within the European Union, PanEuropean Programme on Transport, Environment and Health within UNECE and WHO, Environmentally Sustainable Transport within OECD and Urban Sustainable Travel within ECMT.

\section{B Company Public Transport Fare}

All The Nordic Countries could work on changing the taxable value of company sponsored public transport fare. A common pressure to change the taxable value could accelerate the individual decision-making. The Danish examples need to be followed up. In case the tax scheme is changed in Finland, the effects should be studied and the experiences disseminated in The Nordic Countries. 


\section{Car Parking as a Fringe Benefit}

The Swedish example of car parking as a fringe benefit should be analysed. The principle could be activated in all The Nordic Countries. This so-called "stick measure" should be carried out in connection with some "carrots", e.g. a company sponsored public transport fare. A single stick measure defining car parking as a fringe benefit, with a certain value, will surely gain strong opposition. If directed to the whole labour force at same time and with a reasonable taxable value and period of transition, this measure could be supported.

\section{Company Cars}

The company car system is not very affordable to single persons as such but the psychological effect of such a system is remarkable. The company car should be regarded as complementary "company ticket".

Car-sharing should be better utilised. For employers it is favourable to provide employees the possibility to use car-share cars rather than providing them with their own parking space. For employees the system can provide the possibility to use a car for casual purposes at a reasonable price.

Company cars using more environmentally sound (hybrid, electricity etc.) technologies should have a lower taxable value than combustion engine cars. Free car parking and exemptions could be directed to cars using environmentally sound technologies. There should be some common guidelines for The Nordic Countries.

\section{E Deductions in Commuting}

The impacts of commuting expense deductions are connected to scattered settlement patterns. Long commuter trips and deduction benefits increase car driving and public transport. This is a system where employment policy, in terms of promoting a larger labour pool, and environment policy are clearly contradictory. The question of how to change this structure should be put on the agenda.

\section{F Mileage Allowances}

The mileage allowance system, in any event, should be changed so that if a competitive (time and money wise) public transport connection exists it should be favoured. This is already the situation mainly for the public sector. This policy is in the hands of individual companies that also decide whether work during travelling on duty can be accepted as working hours. The compensation limit is a national decision. The guidelines could be included in collective labour agreements. 
Favouring public transport is "a carrot" for employers also because of road safety reasons.

The mileage allowance from cycling could be the same as for car driving.

\section{G Include Travel Plans in the Building Permit Process}

A common model is needed to include company travel plans within the building permit process. The model would demonstrate how transport (staff, freight, visitors) is to be organised in a sustainable manner and the advantages that employers would gain from this. The guidelines would cover physical conditions at the estate (parking, social premises) as well as models for action. The Nordic Countries have a similar seasonal variation and the modal split differences between summer and winter should be taken into account. The power to activate this model is in the hands of local governments but good examples would clearly make the work easier. Several international examples (GB etc.) can be used in formulating it.

\section{H Model for a Commuter Travel Survey}

A common travel survey model would be useful. Each country's views on the questions to be asked and ways to adapt it to an Internet format should be utilised. Swedish examples, the SMART project, the Norwegian Road Administration and the Danish Association for Municipalities have already made quite a lot of progress on this. Some questionnaires are also available from the Finnish side.

\section{Tax-free Cycling Provisions}

Reasonable, practical, cycling provisions (bicycles for employees, rainwear, maintenance and repair services etc.) should be made available by the employer without tax consequences for the employee. This would promote cycling to work along with better bicycle parking and social premises provisions. This action is a national question and should be discussed separately in each country.

\subsection{Cooperation Actions}

\section{J Nordic Cooperation in Spreading Information via Web Sites}

Several web sites link the experience and the experts. Some of the sites are administered by private companies and some by authorities. For companies it would be useful to find information and Mobility Management 
tools in the domestic language. The national road administrations or ministries dealing with the topic could serve as administrators of such information web sites. There should be one independent web site in each country collecting and linking information on Mobility Management. These web sites could link further to sites provided by consultants etc.

\section{K Annual Nordic Seminar on Recent Development}

An annual Nordic meeting on Mobility Management would be useful for disseminating information and for setting up a network for individuals working actively on Mobility Management issues. The aim of such seminar would be to active new counterparts (e.g. companies, labour administrations and representatives from different transport modes) and to follow up and introduce recent projects. Also the latest EU-projects and their findings should be covered.

The main issues covered in the annual meeting could be following:

- Progress in introducing policy instruments and common Nordic recommendations

- Overview of company projects implemented in each country

- Introducing EU-financed Mobility Management projects

- Developing evaluation methods for Mobility Management actions

The organisations invited to the meeting could be the:

- Related ministries

- National road administration

- Regional and local administration

- Large companies and labour organisations

- Researchers and consultants

The material should be disseminated to larger domestic interest groups. The media should be invited. Study tours could be arranged in conjunction with the seminars.

\section{Campaigning and Networking Activities}

Such campaigns as European Mobility Week and European Car Free day are important awareness raising activities. Cooperation within these European wide activities should be continued and even highlighted in the Nordic cooperation. Also linkage to EPOMM should be ensured from each Nordic country. Participating in annual European Conference on Mobility Management (ECOMM) is a good way for gathering and spreading information among various experts on sustainable transport. Each 
country should utilize the advantage of EPOMM and its best practise information on Mobility Management.

\subsection{Developing Evaluation Methods}

Mobility Management actions need to be evaluated especially from an economic point of view. In case studies presented in this report evaluation has been carried out in several ways but mostly using qualitative parameters e.g.:

- travel questionnaires- before and after surveys on travel behaviour

- health checks

- interviews and questionnaires on the acceptance of a project or single action

Economic parameters had not been used in any of the cases. Bike Busters' did ask project participants how much individual savings had been reached from changing travel behaviour. The project did not, however, calculate any financial costs and benefits for employers.

In Sweden the evaluation of mobility plans has been formulated into a SUMO system (System för utvärdering av mobilitetsprojekt) (picture 7). SUMO is a new system for planning, follow up and evaluating of different actions aiming at affecting traffic and traffic behaviour. SUMO is an advanced version of MOST-MET system adapted to Swedish circumstances in the road traffic sector. MOST-MET is an evaluation tool that was developed in the EU project MOST (Mobility Management Strategies for the next Decades) on Mobility Management during 2000-2002.

SUMO is based on tested methods and based on the concept of measuring the effects at various levels. SUMO is formulated in a simple way and does not differ remarkably from other evaluation systems. The unique part is that with the assistance of SUMO, indicators and results can be displayed at different levels. The system enables tactical evaluation in a project where it is difficult to show short-time results, since a major part of the work focuses on attitudes and behaviour, which is a process that takes a lot of time. SUMO is thus usable in a Mobility Management project where the aim is to gain long-lasting behavioural change in travel habits.

SUMO as well as MOST-MET are systems that could be utilized in planning large and long-lasting Mobility Management projects. The models ensure that relevant indicators and evaluation resources are set and people are committed to them already in the planning phase. The model could also be translated into other Scandinavian languages. Other Mobility Management tools e.g. TAPESTRY (travel behaviour) and OPTIMUM 
(land-use approach) could be as well more easily utilised if they were multi-lingual.

\section{Picture 7. SUMO analysis stages}

\begin{tabular}{l|l|l|l|}
\hline $\begin{array}{l}\text { SUMO's analysis stages } \\
\text { Background } \\
\text { information }\end{array}$ & Y & $\begin{array}{l}\text { External factors } \\
\text { Description of external prequisites. They are same for every user. }\end{array}$ \\
\cline { 2 - 3 } & P & $\begin{array}{l}\text { Individual Factors } \\
\text { Information on personal situation of different inbdividuals, e.g. } \\
\text { grouping to target groups. }\end{array}$ \\
\hline Measures & A & $\begin{array}{l}\text { Useful achievements } \\
\text { Description of the effort made in order to attain a change in } \\
\text { behaviour e.g. meetings, material delivered, data systems, } \\
\text { decision on transport policies etc. }\end{array}$ \\
\hline B & $\begin{array}{l}\text { Knowledge on mobility services } \\
\text { Amout of people being aware of the measures or the project. }\end{array}$ \\
\hline C & $\begin{array}{l}\text { The utilization rate of measures } \\
\text { Amount /proportion of people showing interest toward project or } \\
\text { measures, and mobility measures. }\end{array}$ \\
\hline D & E & $\begin{array}{l}\text { Satisfaction of measures } \\
\text { Measures how satisfied users are with the measures. }\end{array}$ \\
\hline Effects & $\begin{array}{l}\text { Acceptance of measures } \\
\text { Amount /proportion of people accepting alternative measures and } \\
\text { are satisfied with them. }\end{array}$ \\
\hline F & $\begin{array}{l}\text { Established individual behaviour } \\
\text { Amount/proportion of people who have tried new transport modes } \\
\text { or new behaviour. }\end{array}$ \\
\hline G & $\begin{array}{l}\text { Satisfaction of measures } \\
\text { Showing whether people trying a measure are satisfied with it or } \\
\text { not. }\end{array}$ & $\begin{array}{l}\text { Permanent indidual travel behaviour } \\
\text { Amount/proportion of people who have changed their mode of } \\
\text { transport or other travel behaviour. }\end{array}$ \\
\hline $\begin{array}{l}\text { Effects on system } \\
\text { Gives an estimate of how much the transport, emissions, acci- } \\
\text { dents, etc. have been reduced by changed travel behaviour. }\end{array}$ \\
\hline
\end{tabular}

Vägverket 2004

\subsection{Activating companies}

Most promising employer and company segments are:

- Those who have plans to change location and need more information on the impact of relocating for employees including travel costs

- Service sector where employees can be reached by e-mail and information widely disseminated via intranet/internet

- Companies having a quality and environment management system. This, though, is not always a necessary motivator.

- Companies that have huge costs and lack of parking places or problems in employee health. To solve or relieve these problems by Mobility Management, however, needs strong marketing. 
Mobility Management in commuting can be approached from two directions. Behavioural change can be reached by affecting employers that, in turn, provide and market sustainable transport services to their employees. Employers should then be well aware of the other social factors other than commuting which affect single person travel habits. Pendlerkontoret at HUR, partly Vision LundBy and also the SMART project are examples of this kind of employer-oriented approach.

Another possibility is to contact employees directly. In this way knowledge about the psychology behind individual travel behaviour can be understood more easily. The disadvantage is that tools that the employer could provide are not used and that "group pressure and support" is lacking. BikeBusters is an example of an employee-oriented approach. It is not a pure example of Mobility Management because it does not directly activate the employer, the generator of the traffic.

Successful Mobility Management projects use both approaches. In Lundby and also at Pendlerkontoret the contact was directly to the employee but also at a very personal level (single route planning etc.). A successful Mobility Management project needs adequate resources, a long-term commitment from all counterparts and visible improvements. The changes in modal split are most important from the societal point of view. Employees can be activated by economic facts or positive publicity. Employers need a personnel benefit, health factors being one of the most important.

Companies having EMAS or ISO systems may be a bit more interested in this kind of work. If certification does not require actions on transport matters, interest for the project may cease. That is what happened, for example, in one company in SMART. The most important thing is to find companies having real personal interest (e.g. lack of parking spaces, recruitment problems) and active people with high a position and thus power in the companies.

Mobility Management needs public investment. Political support has to be high if the projects are to be long lasting. HUR Pendlerkontor, BikeBusters, Vision Lundby and LundaMats had strong political commitment and quite large budgets that also enabled evaluation.

Visible improvements during the project are crucial. Employees and employers cannot be committed to a long lasting project without direct and visible improvements. In Pendlerkontor, company bikes were seen as a positive action. In Vision Lundby, the "user group in public transport" was one of the most successful actions as well as personalised journey planning. Bike Busters donated free bikes and other equipment to its target group.

The first phase of the project is usually a travel questionnaire. The projects should also have very visible improvements right from the start. Furthermore, the company's administration should be involved well before launching the project to employees. Thus e.g. a new bus stop or bicycle 
route can be achieved very quickly. This motivates people to continue with the effort to promote and use sustainable transport modes.

Encouraging companies to work with Mobility Management can be accomplished primarily in three ways:

- A sustainable mobility plan is required by law or municipal regulation.

- A sustainable mobility plan is required in quality and environment systems.

- Mobility planning and projects are activated and subsidised by the public sector.

There are many potential partners that could and should cooperate in activating companies. At the national level they are mainly:

- Ministry of Transport

- Ministry of Environment

- Ministry of Labour

- Ministry of Health Affairs

- National Road Administration

- All providers of sustainable transport services

At the local and regional level counterparts are municipalities and the regional transport administration. Also employment and economic development centres, as well as regional organizations of health and environment administrations, could take participate. The role of NGO's can be substantial both as a pressure group and as an expert. The role of Association for Municipalities should be significant as it is in e.g. Sweden and Denmark.

Activating and supporting companies in Mobility Management initiatives can in principle be done in two ways:

- by giving information

- by granting finances in order to allow the purchase of mobility expertise as an outsourcing service

At the first stage when companies do not voluntarily act both kinds of support are needed. Also the information should be provided by someone with the resources and authority to act. Recruiting or nominating that kind of person also needs investments. General literary information is important but it is even more important is to have some kind of local focal point which can provide specifics. 
Companies need very practical tools and also marketing material e.g.:

- What kind of benefits employers can gain from Mobility Management.

- How to map current travel habits, problems and expectations.

- What kind actions could be carried out - which are the most effective and what are the costs and benefits.

- How should the selected actions be activated in practice.

- Where to get material for information campaigns.

- How to inform and market about the actions.

- What kind of local rules and national legislation should be taken into account when providing different services.

Every company/organization is different, and there are no universal solutions. Key success factors seem to be:

- Anchoring the project at high levels of management, in order to secure motivation and resources for sufficient periods of time.

- Full finance by public authorities should be considered in "pioneering phase".

- Sufficient time for the project to develop and bring about results.

- Adequate resources for practical work with companies.

- Well-defined and segmented target groups.

- Personal skills and motivation of the people in charge.

- Carefully planned before/after-surveys with sufficient time in between.

- Well-defined and well-known goals and targets.

- Sufficient marketing, resources and patience. 


\section{Appendices}

\subsection{Websites}

\section{Sweden}

www.mobilitymanagement.se

Website provides information and links to Swedish, European and worldwide Mobility Management activities. This informative website covers theory, practice, news, an information forum and contacts about Mobility Management. Several documents are possible to download. Some of the information is also available in English.

On the national level, Swedish National Road Administration's website contains information about Swedish Mobility Management activities. Good practices in sustainable transport are found on www.vv.se/i_miljo.shtml and Mobility Management activities on www.vv.se/vag_traf/mobility/index.shtml. Information in English is partially available.

www.ieh.se/transport/

IEH's website provides information about sustainable transport www.naturvardsverket.sel

The Swedish Environmental Protection Agency's website contains information about national and regional actions on sustainable transport.

www.visionlundby.goteborg.se

Information on Vision Lundy can be found on the project's own website. A great part of the information is also available in English. www.lund.se/leva_i_lund/9_trafik_kommunikation/4_lundamats/ Another recognised Mobility Management project is LundaMats. Information in English is available.

www.epomm.org

Sweden is a member of the European Platform on Mobility Management EPOMM.

\section{Denmark}

www.hur.dk/plan/pendlerkontor

The Greater Copenhagen Authority - in Danish: Hovedstadens Udviklingsråd (HUR) website provides basic information about Mobility Management. The website includes information about traffic and transport plans, marketing and telecommuting. There are also some information 
and practical tips about car-pooling and a lot of information about cycling.

www.cogita.dk

Cogita is a regional network for environmental work and Mobility Management. It is wide in scope dealing with issues such as children, housing, retail \& trade and transport.

Transport focuses on Mobility Management. The Transport and Mobility section contains information about:

- Commuter plan

- Carpooling

- Car-sharing

- Bicycle campaigns

- Road Safety

- Transport Behaviour

www.pendler.net

Pendler.net is a database, where one can sign in if willing to share a car in commuting. The database gives a partner, who has the same route. A lot of emphasis is paid also to marketing the car-share idea.

www.trivector.se

In Sweden, courses on Mobility Management for companies are held by the consultant Trivector.

Norway

www.arbeidsreiser.no

Norwegian bicycle federation has produced a website that contains:

- guidelines for cost-benefit analysis for measures being taken

- a transport behaviour survey

- a tool for creating environment accounts connected to transport (survey data for employees transport demand and behaviour)

- descriptions of efforts and "best-practice"

www.transportiby.net

The websites include information about different projects and also some information about travel plans. Projects are closely related to Mobility Management issues.

\section{Finland}

www.ymparisto.fi/default.asp? contentid $=84175 \&$ lan $=E N \&$ clan $=f$

Information on sustainable transport policy and the program "Moving Finland" can be found from this Ministry of Environment website. 
www.mintc.fi/www/sivut/suomi/ymparisto/elli/teema5_index.html Information on transport and environment can be found from this Ministry of Transport and Communications website.

A website on sustainable transport services and Mobility Management issues is going to be opened in 2005. The Ministry of Transport and Communications together with Ministry of Environment will administer the site.

\subsection{Reference literature}

AalborgUniversity 2000. Evaluering af CykelBus'ter projektet, 1999-2000. Transport Research Group at Aalborg University. Denmark.

Elmkvist, Päivi (2003) SMART Road User - Individual marketing campaign for environmentally sound transports Lunds kommun Tekniska förvaltningen. Conference Paper ECOMM Karlstad 2003. Germany.

Haas, Mette 2003. HUR Pendlerkontor. Trafikdage i Aalborg University 2003. Conference paper. Denmark.

HUR Pendlerkontor 2004. Mobility Management på virksomhedsniveau. Evaluering af Pendlerkontorets forsøg med transportplaner i Hovedstadregionen, efterår 2002 - forår 2004. HUR Pendlerkontor. Denmark.

\subsection{Interviews}

Elmkvist, Päivi. Project Manager Lund Mobility Centre, Lunds kommun 16.09.2004. Sweden

Eriksson, Göran. Head of the Technical Services Department, Lunds kommun 15.09.2004. Sweden

Laine, Kimmo. Chief Executive Officer. City Car Club. November 2004. Finland.
Hyllenius, Pernilla 2003. Soft measures affect traffic in Lund - effects from two years work with a sustainable transport system in Lund, Trivector Traffic AB. Conference Paper ECOMM Karlstad 2003. Germany.

Hyllenius, Pernilla \& Lyborg, Jessica 2001. LundaMaTs ger resultat. Trivector Kortversion av rapporten Uppmärksamhet och effekter av LundaMaTs. Sweden. Liikenne- ja viestintäministeriö 2004. Joukkoliikenne nousuun. Työryhmän mietintö Liikenne- ja viestintäministeriön julkaisuja 51/2004. Finland.

Vägverket 2004. System för utvärdering av mobilitetsprojekt. Publikation 98/2004. Sweden.

Ympäristöministeriö 2003. Liikenne $y h$ dyskunnan suunnittelussa. Ympäristöministeriön ympäristöopas 104. Finland.

Lindau, Johan. Smarter communication for companies manager, Vision Lundby, 07.10.2004. Sweden.

Sundell, Lisa. Project Manager, Vision Lundby and head of the unit Mobility Management, Gothenburg 17.09.2004. Sweden. 